UNIVBRSIDADE DB 8XO PAULO - USP

INSTITUTO DB CIÊNCIAS MATEMXTICAS DE SXOO CARLOS - ICMSC

\title{
PROBLEMA DE CORTE BIDIMENSIONAL GUILHOTINADO NÃO-ESTAGIADO E IRRESTRITO
}

SILVANA AP. BORSBTTI GREGÓRIO VIDOTTI

orientador: Prof. Dr. Marcos Nereu Arenales

Dissertação apresentada ao Instituto de Ciencias Matemáticas de são Carlos, da Universidade de Sắo Paulo, como parte dos requisitos para obtençăo do titulo de Mestre em Ciências: áreas - ciências de Computação e Matemática Computacional.

Săo Carlos - 1993 
A minha Pamilia. 
Ao Bcio, com amor. 
"No meu coração

Um foco de luz

Seduz a razão

De repente a visão da esperança !"

(Eduardo Gudin - Costa Metto) 


\section{AGRADECIMENTOS}

Aos meus pais e irmáos pelo carinho, apoio - confiança sempre presentes.

Ao Bcio, pela paciéncia, carinho a amor demonstrados durante estes anos, o que contribuiu sensivelmente para realização deste trabalho.

Ao Prof. Dr. Marcos Nereu Arenales pela orientaḉo e apoio na preparaçăo deste trabalho.

Aos Profs. Dr. Reinaldo Morábito Neto e João Batista Ernesto de Moraes pelo apoio técnico.

A familia Zucchi Vidotti pelo incentivo.

A Plácida e ao Marcos pelo apoio e incentivo.

'A UNESP, pela viabilização deste trabalho, bem como pelo apoio financeiro parcial.

Ao CNPq, pelo apoio financeiro parcial.

A Deus, ’a Aparecida e ao António, pelo apoio espiritual.

Aos colegas da Faculdade de Filosofia e Ciencias UNESP / Campus de Marilia, da Faculdade de Ciencias UNESP/Campus de Bauru, e a todos aqueles que direta ou indiretamente colaboraram para a realização deste trabalho. 
o objetivo geral deste estudo é o de trabalhar o problema de corte bidimensional guilhotinado irrestrito e năo-estagiado. Para tanto, foram revistas regras e heuristicas a serem utilizadas $\theta$ foi sugerida uma combinação da regra de simetria com a heuristica de gexação dos pontos de cortes possiveis. Uma abordagem em grafo-E/OU, com a utilizaçáo de uma estratégia hfbrida, que combina as técnicas "Hill-Climbing" e "Depth-Pirst" para a busca em grafo, foi utilizada para a resoluçáo do problema. Finalmente, foram comparados os resultados obtidos com resultados apresentados na literatura.

Palavras-chave: problema de corte bidimensional, padrăo de corte guilhotinado irrestrito e náo-estagiado, grafo-B/OU. 
The general purpose of this study is to deal with the non-staged unconstrained guilhotined cutting problem. For this, rules and heuristics in use are reviewed and a combination between simmetry rule and possible cuttings points generation heuristics in suggested. An AND/OR-graph approach, with used a hibrid strategy that combines Hill-Climbing and Depth-First techniques, in order to search the graph, was used to solve this problem. Pinally, results from this study and results presented in the literature are compared.

$$
\begin{gathered}
\text { Key-words: two-dimensional rerting problem, non-staged } \\
\text { unconstrained guilhotined cutting } \\
\text { AND/OR-graph. }
\end{gathered}
$$




\section{SUMÁRIO}

Introdução

2

Conceitos básicos

2.1 .

Definição dos problemas de cortes

2.2 .

Problemas relacionados

2.2.1.

Problema de Empacotamento

2.2 .2 .

Problema de Carregamento de Veiculos

2.2 .3 .

Problema de Alocação de Tarefas

2.2 .4 .

outros problemas

3. Classificação dos problemas de corte

3.1 . Dimensão

3.1.1.

Problema Unidimensional

3.1.2.

Problema Bidimensional

3.1.3.

Problema Tridimensional

3.1 .4 .

Problema M+0,5-dimensional

3.1 .5 .

Problema Multidimensional

3.2 .

Formato da figura

3.2.1.

Forma

3.2. 2 .

Tamanho

3.2 .3 .

Orientação

3. 3 .

Agrupamento

3.4 .

Disponibilidade

3.5 .

Padrão de corte

3.5 .1 .

Restrição de distancia de corte

3.5 .2 .

Restrição de orientação

3.5 .3 .

Restrição de frequência

Tipo de corte

3.6 .

Forma de alocação

3.6 .1 .

Alocação por seleção de objetos 25

3.6.2.

Alocação por seleção de itens

3.7 . objetivos 
Problema de corte bidimensional guilhotinado nao-estagiado e irrestrito

4.1 .

Descrição

4.2 .

Redução de cortes possiveis

4.2.1. Discretizaçăo

4.3 .

Eliminaçăo de padróes equivalentes 35

4.3 .1 . simetria

4.3.2.

ordenaçăo 36

4.3.3.

Exclusăo

4.4.

Limitantes inferiores e superiores

4.5 . Heuristicas

4.5.1.

Discretizaçầo de Beasley

4.5 .2 .

Limitantes heuristicos

4.6 .

Fórmula recursiva de Beasley

4.7 .

Formula de Christofides e Whitlock

5.

Representação em grafo E/OU

5.1 .

Conceitos básicos

5.2 .

Estratégias de busca

5.2 .1

Busca em Largura-primeiro

5.2 .2 .

Busca em Profundidade-primeiro

5.2.3.

Busca da Escalada

5.2 .4 .

Busca pelo Melhor-primeiro

5.2 .5 .

Busca hibrida

6. Resultados computacionais 54

6.1. Discretização $\quad 54$

6.2. Procedimento HC_DF2 57

6.2.1. Combinação da regra de simetria com a $\begin{array}{ll}\text { heuristica de Beasley } & 57\end{array}$

6.2.2. Parâmetros 59

7. Conclusỗes 66

$\begin{array}{ll}\text { Referências bibliográficas } & 67\end{array}$ 


\section{FIGURAS}

2.1.a. Objetos $\quad 8$

2.1.b. Itens 18

2.1.c. Soluçáo para o problema 9

3.1.1. Padrão de corte unidimensional 14

3.1.2. Padrão de corte bidimensional 15

3.1.3. Padrão de corte tridimensional 15

3.1.4.a. Padrão de corte 1,5-dimensional 16

3.1.4.b. Padrão de corte 2,5-dimensional 16

3.2.1. Figuras regulares e irregulares 18

3.5.4.a. Padrões de cortes guilhotinados e não guilhotinados 23

3.5.4.b. Padrắo de corte 3-estagiado 24

4.1. Padrốes de cortes dados por $(1,0,3,2,0) \quad 32$

4.2. Padrăo de cortes homogênenos 34

4.3.1. Duplicação de padrões - simetria 35

4.3.2. Duplicação de padrões - ordenação 36

4.3.3. Exclusão da peça i 37

5.1.a. Sequência de cortes sobre A 43

5.1.b. Padrẫo de cortes sobre A 44

5.2.5. Estratégias de buscas hibridas 49 


\section{TABELAS}

3.1. Dimensão dos problemas 17

3.2. Problemas associados a combinação de tipos 29

6.1. Exemplo apresentado por Beasley 55

6.2 Soluções para o problema de Beasley 58

6.3. Variações dos parâmetros - HC_DF2 60

6.4. Exemplos gerados aleatoriamente 61

6.5. Soluções para os problemas aleatórios 62

6.6. Soluções dos problemas aleatorios $(L, W)=(1000,1000) 63$

6.7. Exemplo apresentado em Morábito et al. (1991) 64

6.8. Soluçôes dos problemas aleatórios da tabela $6.7 \quad 64$

\section{GRÁFICOS}

6.1. Heurística de Beasley x Escolha aleatória 55

6.2. Heurística de Beasley $x$ Escolha aleatoria restrita 56 


\section{INTRODUÇÃO}

Um problema de corte consiste em cortar um objeto em pequenos 1tens, de modo a otimizar uma função objetivo, como por exemplo, minimizar a perda de material. Para a resolução deste tipo de problema foram propostas, por vários autores, diferentes abordagens e restriçóes.

o objetivo deste estudo é trabalhar o problema de corte bidimensional guilhotinado nåo-estagiado e irrestrito, que consiste em cortar uma placa retangular em peças pré-determinadas de maneira a maximizar o valor total peças produzidas.

Avalia-se a heuristica de discretização de Beasley (1985a) e apresenta-se uma nova escolna dos pontos de discretizaçôes de cortes possiveis, finalizando com a comparação dos resultados computacionais.

No capitulo 1 , introduz-se um breve historico dos problemas de cortes apresentados na literatura.

Conceitos básicos dos problemas de cortes e alguns problemas relacionados a estes, são apresentados no capitulo 2 .

Uma classificação de problemas de cortes, bem como uma tipologia para tais problemas, proposta por Dyckhoff (1990), com a finalidade de unificar os diferentes usos de notações na literatura e concentrar pesquisas em tipos especiais de problemas, são apresentadas no capitulo 3 .

Uma descrição formal de um problema de corte bidimensional guilhotinado não-estagiado e irrestrito, bem como regras e heurísticas a serem consideradas na resolução de referido problema, são apresentadas no capitulo 4. 
Uma abordagem om grafo-B/OU proposta por Morábito et al.(1989), com a utilização da estratégia de busca hibrida "Hill-Climbing" e "Depth-First - Backtracking", para a geraç̃o dos padröes de cortes para o problema estudado 6 apresentada no capitulo 5 .

No cap1tulo 6, sáo comparados os resultados obtidos com resultados apresentados na literatura. Finalmente, uma conclusão é apresentada no capitulo 7 . 


\section{HISTÓRICO}

Os problemas de cortes têm sido estudados por inúmeros pesquisadores de várias áreas do conhecimento, ao longo das últimas décadas.

Bntre os primeiros trabalhos estão 0 de Kantorovick, que apresentou em 1939 uma formulação matemática para o Problema Unidimensional, e o de Brooks et al. - 1940, com a elaboração de um método para o corte de peças retangulares, citados em Dyckhoff(1990); e o de Paull e Wallter (1955), com a modelagem do problema unidimensional como um problema de programaçâo matemática.

Problemas com a mesma estrutura logica foram enfocados na literatura de maneiras diferentes. Como exemplos, temos o problema de corte de estoque e o da perda de apara, o de empacotamento de caixas (bins) e o da mochila. Tal fato provavelmente ocorreu em virtude de os pesquisadores serem de diferentes áreas do conhecimento como: Engenharia, Matemática, Ciência da Computação, etc., e das aplicações serem para vários tipos de indústrias.

Eisemann (1957) denominou o Problema Unidimensional como Problema da Apara, enquanto Gilmore e Gomory (1961) enfocaram tal problema como Problema de Corte de Bstoque.

Problemas de corte de estoque unidimensionais podem ser resolvidos por programaça linear. Geralmente, os problemas práticos envolvem milhões de variáveis de decisão, tornando inviável a sua resolução por meio de programação linear. Preocupados com isto, Gilmore e Gomory (1961) desenvolveram um procedimento que supera a dificuldade básica dada pelo problema de inúmeros padrões de cortes, dado em programação linear pelo problema de geração de muitas colunas. Tal procedimento envolve a 
cada iteraç⿰丿丶⿱⿴囗十丌 do algoritmo simplex, a soluçáo de um problema auxiliar conhecido como Problema da Mochila, o que permitiu um aumento significativo no número de variáveis para o problema, pois estas foram consideradas implicitamente.

Gilmore e Gomory (1963) descreveram uma adaptaçáo e aplicação do método por eles anteriormente desenvolvido (1961) para o problema especifico da apara de papel. Mudanças foram apresentadas na formulação, para uma maior flexibilidade da demanda, fazendo com que ela pertencesse a um intervalo aceitável pelo cliente, e o algoritmo foi adaptado para que pudesse ser utilizado para outras situaçóes como cortes de tubo de metal, aço ou rolo de papel. celofane, etc. Vale salientar que este algoritmo continua sendo um dos bons algoritmos para problemas de cortes de estoque unidimensional.

Procedimentos heuristicos, baseados no conceito de redução do problema, foram apresentados por Haessler (1971) e Tilanus e Gerhardt (1976), juntamente com idéias de penalização e aplicaçôes para as indústrias de papel e aço.

Em 1965, Gilmore e Gomory estudaram os problemas de corte de estoque bidimensional e multidimensional, tendo como objetivo a minimização do número de placas de estoque a serem utilizadas para atender a demanda requerida. Apresentaram ainda um algoritmo para geração de pađrões de cortes guilhotinados $2(3)$-estagiados e irrestritos.

Um algoritmo recursivo de busca em grafo foi apresentado por Herz (1972) para o problema bidimensional, e sua implementação fornece rapidez na solução do problema de corte de estoque irrestrito e guilhotinado. Ele utilizou discretizações dos possiveis pontos de cortes e limitantes para a busca em grafo, além de comparar este método com os outros dois métodos apresentados anteriormente por Gilmore e Gomory (1966). 
Dyson e Gregory (1974) apresentaram uma heuristica para - sequenciamento dos padróes de corte, utilizando programaçáo linear para a resoluçăo do problema de corte bidimensional de vidro, porém chegaram a conclusáo de que o sequenciamento de padróes năo foi satisfatório para o caso especifico.

Um algoritmo de busca em árvore para problemas bidimensionais guilhotinados e restrito foi apresentado por Christofides e Whitlock (1977). Eles utilizaram técnicas de programação dinamica para a resolução do problema, além de utilizarem o problema de transporte como limitante superior para o processo de busca. Os resultados indicam que o algoritmo é um procedimento eficaz na resolução de problemas de tamanho médio.

Modificações no algoritmo de Gilmore e Gomory foram propostas por Haessler (1980) visando a ampliação da função objetivo para além da minimização de perda de material.

Um estudo do problema de corte de estoque bidimensional irrestrito, nas versôes estagiado e não-estagiado, foi apresentado por Beasley (1985a), sendo utilizada a formulação de programação dinâmica e heurísticas para problemas de tamanho grande.

- problema de gerar padrões de cortes ortogonais nâo-guilhotinados e restritos foi modelado matematicamente por Beasley (1985b) como um programa linear 0-1. Este propôs ainda, um método "Branch-and-Bound" para resolvê-lo, com auxilio da relaxação Lagrangeana. Devido ao número elevado de restrições e variáveis envolvidas, o autor recorreu a soluções heuristicas.

Arcaro (1988) propôs modificações para o modelo de corte de estoque unidimensional de Gilmore e Gomory, que vieram a melhorar as características das soluçöes geradas. Tais modificações foram feitas no conjunto de restrições e na função objetivo, ao invés de minimização de perda de material, a maximização dos lucros, por julgar ser este o objetivo real das 
empresas. Bstudou especificamente o problema de corte de bobinas de papel.

Morábito (1989) revisou e propos modificaçoses em algumas técnicas de resoluçáo aplicadas ao problema de corte de estoque bidimensional, além de apresentar uma nova representação do problema de geraçăo de padróes de cortes em grafo-B/OU.

- periódico "European Journal of Operations Research" publicou, em 1990, um número especial com enfoque em problemas de cortes de estoque e de empacotamento. Bntre os artigos desta ediç̃o pode-se destacar os que tratam especificamente do problema de corte como o de Dyckhoff (1990), que apresenta uma tipologia integrando as várias espécies de problemas de cortes e empacotamento, tendo como propósito a unificação das diferentes notaçôes na literatura, e o artigo de Dagli (1990), que apresenta uma arquitetura de sistema baseado em conhecimento, para a geração de padrões de cortes para a resolução do problema de corte de estogue.

Ainda no periódico (op. cit), uma outra abordagem foi apresentada por Ferreira et al. (1990), com enfoque a problemas aplicados à indústria de ferro e aço, objetivando o planejamento de cortes de rolos em duas fases. O trabalho de sweeney e Haessler (1990), para problemas bidimensionais de corte de rolos com múltiplos graus de qualidade, e o de Farley (1990), aplicado a indústria de lona, com algoritmo heurístico que envolve uma forma modificada do algoritmo 3-estagiado de Gilmore-Gomory combinado com técnicas de programação inteira, também merecem destaque.

Heurísticas para o sequenciamento de padrôes de corte foram apresentadas por Yen (1991) para problemas de cortes de vidro.

Morábito e Arenales (1991, 1992a) trataram do problema de corte bidimensional guilhotinado de tamanho grande, 
discutiram a heuristica proposta por Beasley (1985a) e a possibilidade de impor como heuristica o corte 2-estagiado, como limitante no processo de resoluçăo.

Morábito et al. (1992) propuseram uma estrutura de grafo-E/OU para a representação da solução do problema de corte bidimensional guilhotinado náo-estagiado e irrestrito. 0 método heuristico de busca em grafo apresentado combina as estratégias de busca "Depth-Pirst" e "Hill-Climbing". Bstenderam esta abordagem de representação do problema em um grafo-E/OU para o problema de corte bidimensional estagiado e restrito (Morábito e Arenales, 1992b), bem como para o problema de empacotamento de contêineres (Morábito, 1992). 


\section{CONCEITOS BÁSICOS}

Neste capitulo são introduzidas noçóes básicas dos problemas de cortes, bem como apresentados alguns problemas relacionados ao tema.

\subsection{Definiçăo dos problemas de cortes}

Genericamente, Problemas de Cortes consistem em cortar objetos a fim de produzir itens requeridos em quantidades prédeterminadas, de maneira a otimizar, isto é, maximizar ou minimizar determinados objetivos. Problemas de Cortes podem ser encontrados, por exemplo, no corte de papel, madeira, vidro, plástico, tecido, couro, aço, bem como no carregamento de paletes e contêineres.

A figura 2.1.a ilustra objetos (retângulos maiores) que se encontram disponiveis em estoque para a produção de itens (retângulos menores) pré-determinados - figura 2.1.b.
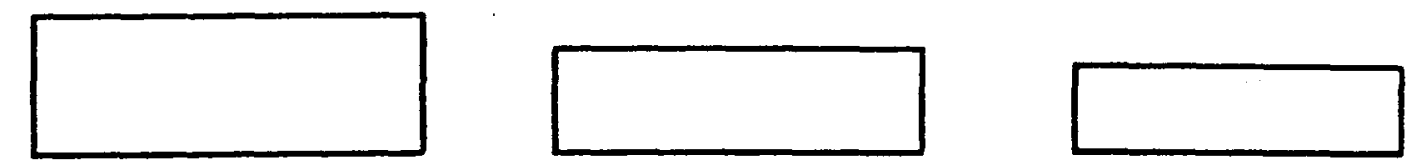

figura 2.1.a - Objetos
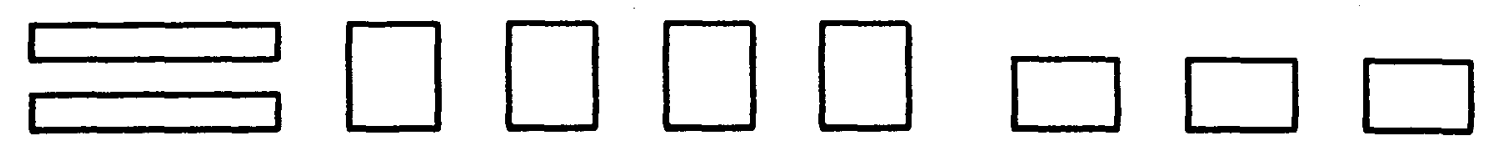

figura 2.1.b - Ítens 

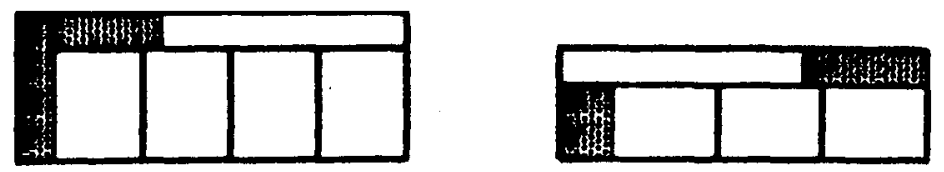

figura 2.1.c - Solução para o problema

Cortar objetos a fim de produzir itens é análogo a combinar itens em objetos, e esta combinação é denominada padrão de corte. A figura 1.c ilustra padróes de cortes para objetos da figura 1.a, utilizando itens da figura 1.b.

A área hachurada representa a sobra de material, denominada apara, resultante deste padrão de corte.

A melhor solução será dada pelo melhor padrão de corte, segundo um objetivo estabelecido, que geralmente corresponde a preencher o maior espaço possivel dos objetos.

Um possivel objetivo, quando os objetos são idênticos, poderia ser o de minimizar a quantidade de objetos a serem utilizados na produção de todos os itens pré-determinados. Considera-se, neste caso, que o conjunto de objetos em estoque seja suficiente para produzir todos os itens requeridos; como sub-produto tem-se uma seleção de objetos a serem cortados a fim de produzirem itens requeridos. Um problema com tal objetivo é denominado Problema de Corte de Estoque.

Em contraposição ao problema anterior, se o conjunto de objetos em estoque não fosse suficiente para produzir todos os Itens requeridos, seria definido um outro problema, cujo objetivo passaria a ser o de maximizar o valor total de itens escolnidos, utilizando para tanto todos os objetos, onde a cada item associa-se um valor unitário. 
Considerando-se que cada item tem um valor associado ao espaço ocupado por ele, pode-se dizer que a soluçăo otima para o problema é dada pelo máximo espaço ocupado pelos itens. Neste caso, tem-se como sub-produto uma seleçó de itens a serem produzidos.

supondo-se um problema em que os objetos a serem cortados possuam uma única dimensão de corte na determinaçăo da solução, temos que o universo de soluçőes para o problema é restrito a combinaçôes geométricas dos itens ao longo da única dimensão relevante desses objetos. Este tipo de problema é tratado na literatura por Problema de corte Unidimensional. Exemplificando, tem-se o corte de tubos de PVC, barras de ferro, bobinas de papel, etc.

o exemplo da figura 2.1. é um caso particular do Problema de Corte em que os objetos e os itens possuem formas retangulares, e podem ser cortados ao longo do comprimento e da largura, o que implica em duas dimensões relevantes para a determinação do problema.

Tal problema é denominado Problema de Corte Bidimensional, e seu universo de soluções consiste nas combinações geométricas dos itens ao longo do comprimento e da largura dos objetos. Exemplos são encontrados no corte de madeira, vidro, papel, etc.

Analogamente, pode-se denominar Problema de Corte Tridimensional ao problema em que três das dimensões são relevantes para determinação da solução. Portanto, as combinaçốes geométricas dos 1tens ao longo das três dimensôes relevantes representam o universo de soluçôes. Como exemplo, tem-se o o corte de blocos de espuma.

Genericamente, classifica-se um problema em função de suas dimensôes relevantes. Uma classificação mais detalhada dos 
Problemas de Cortes é exibida no Capitulo 3. A seguir, 8ăo apresentados alguns problemas relacionados com 0 Problema de Corte.

\subsection{Problemas relacionados}

A estrutura lógica dos problemas de corte possui caracteristicas básicas dadas pelos objetos e itens definidos geometricamente e pela combinação dos itens dentro dos objetos. Problemas com estas mesmas caracteristicas, com dimensões espaciais (comprimento, largura e altura), ou ainda não espaciais (peso e tempo) são descritos abaixo.

\subsubsection{Problema de Empacotamento}

Analogamente ao problema de cortes, pode-se pensar em empacotar (arranjar) itens dentro de objetos, de maneira a minimizar o volume total dos objetos necessários para empacotar todos os itens, ou ainda minimizar o número de objetos a serem utilizados.

Este problema é comumente conhecido na literatura como Problema de Empacotamento. Exemplos podem ser encontrados no empacotamento de caixas ("bins"), no carregamento de paletes e no carregamento de contêineres.

Tal analogia foi inicialmente percebida por Gilmore e Gomory (1965) ao enfocarem que o empacotamento de caixas em vagões ferroviários poderia ser visto como cortar paralelepipedos pequenos a partir de paralelepipedos grandes.

Por serem considerados análogos, são tratados como problemas de corte ou problemas de corte/empacotamento. Para um 
estudo mais aprofundado sobre os Problemas de Bmpacotamento consultar Morábito (1992).

\subsubsection{Problema do Carregamento de Velculos}

Este problema foi apresentado por Eilon e Christofides (1971) e consiste em minimizar o número de veiculos a serem utilizados no transporte de uma certa quantidade de carga, tendo como restrições os critérios de lotação e de peso permitidos para cada veiculo.

2.2.3. Problema de Alocação de Tarefas

- problema de alocação de tarefas consiste em minimizar - número de dias de trabalho necessários ao desenvolvimento de $\mathbf{n}$ tarefas, que utilizam $m_{i}$ unidades de mão-de-obra $e t_{i}$ horas de trabalho, $i=1, \ldots, n$, em uma fábrica com $M$ unidades de mão-de-obra $e$ $T$ horas disponiveis por dia. Ao considerar outros recursos, este problema torna-se multidimensional.

2.2.4. Outros problemas

Outros problemas relacionados com o Problema de Cortes foram citados em Dyckhoff (1990) e em Morábito (1992). Por exemplo, os problemas de Balanceamento de Linha de Montagem, Programação de Multi-Processador, Orçamento de Capital, Alocação de Memória no Computador e Alocaçáo de Arquivos. 


\section{CLASSIFICAÇÃO DOS PROBLEMAS DE CORTE}

Uma primeira classificaçăo dos problemas de corte foi feita na seção 2.1, e tinha como sub-produtos a seleçăo de objetos a serem cortados e a seleçăo de itens a serem produzidos.

A seguir, é apresentada uma classificação detalhada dos problemas de cortes, considerando a dimensão, formato, agrupamento, disponibilidade, padrăo de corte e forma de alocaçăo de itens em objetos, além dos objetivos dos problemas. Dyckhoff (1990) apresentou uma efetiva comparação dos problemas de corte/empacotamento e sugeriu uma notaçấo reduzida para os diversos casos apreentados na literatura.

\subsection{Dimensão}

Normalmente os Problemas de Corte/Empacotamento são apresentados na forma tridimensional do espaço Euclideano, mas nem sempre as três dimensốes espaciais (comprimento, largura e altura) são significativas na resolução dos problemas. Por isso, estes problemas são classificados em função de suas dimensôes relevantes.

As dimensões de um problema podem ser espaciais, do tipo comprimento, largura e altura, e/ou não espaciais, como peso (cf. Dantizg, 1957; Eilon e Christofides, 1971), tempo (cf. Coffman et al., 1978) e financeira (cf. Lorie e Savage, 1955; Martello e Tohl, 1980), citadas em Dyckhoff (1990).

\subsubsection{Problema Unidimensional}

No problema unidimensional somente uma dimensão é 
significativa na determinaçó da soluçóo. Bxemplos podem ser encontrados nos cortes de barras de aço, tubos de PVC, bobinas de papel ou aço, etc..

A figura 3.1 .1 representa um padráo de corte no qual o objeto de comprimento L deverá ser cortado em 1tens, ao longo do comprimento, produzindo assim 1 tens de dimensáo $l_{i}, i=1, \ldots m$, onde m representa 0 número de tipos diferentes de itens a serem produzidos. Como tem-se uma única dimensáo relevante para a determinação do problema, pode-se denominar este padrấo como sendo um padráo de corte unidimensional.

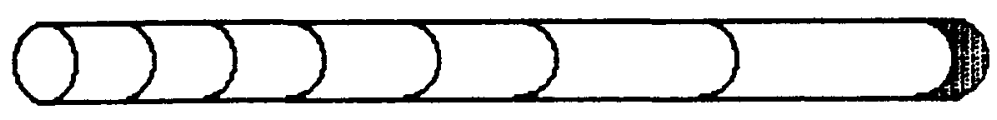

figura 3.1 .1

Padrão de corte unidimensional

\subsubsection{Problema Bidimensional}

No problema bidimensional, duas dimensões são relevantes na determinação da solução. Cita-se como exemplos o corte de placas de vidro, madeira e papel, com altura (espessura) constante.

A figura 3.1 .2 representa um Padrão de Corte Bidimensional em que o objeto de dimensões ( $L, W$ ) foi cortado em 1tens de dimensões $\left(1_{i}, w_{i}\right), i=1, \ldots, m$. Neste caso as dimensôes relevantes para os cortes sấo o comprimento e a largura, enguanto que a altura é constante. 
figura 3.1.2

Padrão de corte bidimensional

\subsubsection{Problema Tridimensional}

No problema tridimensional, três dimensões são significativas na determinação da solução. Como exemplo, suponha que um objeto de dimensões ( $L, W, H$ ) deva ser cortado em m itens pré-determinados de dimensões $\left(l_{i}, w_{i}, h_{i}\right), i=1, \ldots, m$.

Alguns problemas tridimensionais, ao serem resolvidos, são reduzidos a problemas bidimensionais, como é o caso do Problema de Carregamento de Paletes que comumente é resolvido como um problema bidimensional de arranjar camadas de itens tridimensionais de mesma altura sobre o palete.

A figura 3.1.3 representa um padrấo de corte para um problema tridimensional.

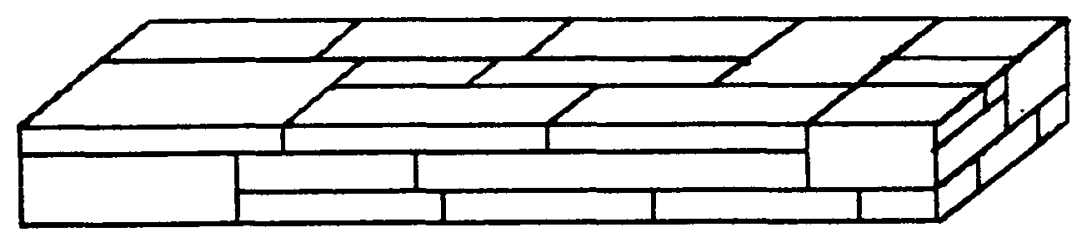

figura 3.1 .3

Padrão de corte tridimensional 
No problema $[M+(0,5)]$-dimensional, $M 21$ : inteiro, temos $(M+1)$ dimensóes relevantes na resoluçáo do problema, porém $M$ dimensôes sáo fixas e a dimensão restante é variável. Um exemplo 1,5-dimensional é dado pelo corte de uma bobina de papel com largura fixa e comprimento variável, que pode ser calculado em função dos itens requeridos.

A figura 3.1.4.a ilustra um padráo de corte de um problema 1,5-dimensional no qual a largura $w$ é fixa e o comprimento L é variável.

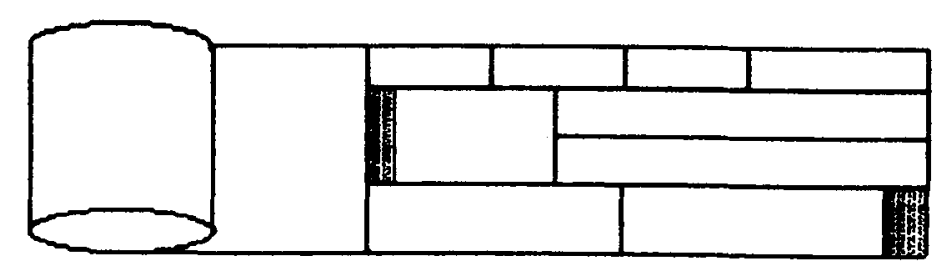

figura 3.1.4.a

Padrão de corte 1,5 -dimensional

Um exemplo 2,5-dimensional é dado por um paralelepipedo de espuma de altura e largura conhecidas e comprimento a ser determinado em função dos itens requeridos, como colchốes, tavesseiros ou almofadas.

A figura $3.1 .4 . b$ exibe um padrão de corte 2,5-dimensional com as dimensões de largura w e altura H fixas e o comprimento L variável.

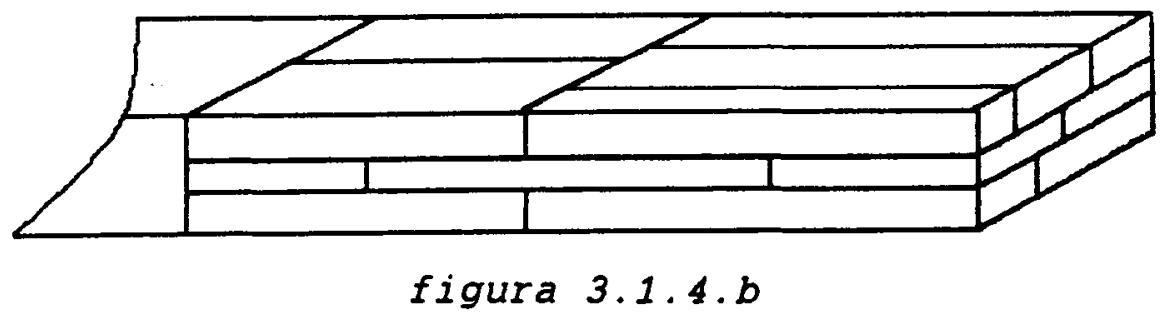

Padrắo de corte 2,5-dimensional 


\subsubsection{Problema Multidimensional}

Considera-se como multidimensional o problema em que mais de três dimensóes săo relevantes na determinaçáo da soluçăo. Neste tipo de problema pelo menos uma das dimensóos a náo espacial.

Bxemplificando tem-se o Problema de Alocaçáo de Tarefas que consiste em minimizar . o número de dias necessários ao desenvolvimento de $n$ tarefas pré-definidas, utilizando $R_{i j}$ recursos do tipo $j$ por dia de trabalho, $i=1, \ldots, n, j=1, \ldots, m$.

A tabela 3.1 sintetiza a classificaçáo dos problemas quanto as dimensôes relevantes, bem como os exemplos mais comumentes enfocados.

$$
\text { tabela } 3.1
$$

Dimensão dos problemas

\begin{tabular}{|c|c|c|c|}
\hline Problema & $\begin{array}{l}\text { Dimensốes } \\
\text { Relevantes } \\
\text { Fixas }\end{array}$ & $\begin{array}{l}\text { Dimensóes } \\
\text { Relevantes } \\
\text { Variáveis }\end{array}$ & $\begin{array}{l}\text { Bxemplos } \\
\text { (cortes/em- } \\
\text { pacotamento) }\end{array}$ \\
\hline Unidimensional & comprimento & & $\begin{array}{l}\text { barra de aço } \\
\text { tubo de PVC }\end{array}$ \\
\hline Bidimensional & $\begin{array}{l}\text { comprimento } \\
\text { largura }\end{array}$ & & $\begin{array}{l}\text { papel, vidro, } \\
\text { aço, madeira }\end{array}$ \\
\hline Tridimensional & $\begin{array}{l}\text { comprimento } \\
\text { largura } \\
\text { altura }\end{array}$ & & $\begin{array}{l}\text { palete, } \\
\text { contêiner } \\
\text { caixas (bins) }\end{array}$ \\
\hline 1,5-dimensional & largura & comprimento & $\begin{array}{l}\text { bobina de } \\
\text { papel, tecido }\end{array}$ \\
\hline 2,5-dimensional & $\begin{array}{l}\text { largura } \\
\text { altura }\end{array}$ & comprimento & $\begin{array}{l}\text { bloco de } \\
\text { espuma }\end{array}$ \\
\hline Multidimensional & $\begin{array}{l}\text { tempo de pro- } \\
\text { duçấo, mâo-de } \\
\text { obra, tempo } \\
\text { de máquina, } \\
\text { energia }\end{array}$ & & $\begin{array}{l}\text { alocaçäo de } \\
\text { tarefas }\end{array}$ \\
\hline
\end{tabular}


Uma das principais caracteristicas dos problemas de cortes é o formato das figuras dos objetos e 1tens. Bsta caracteristica está diretamente relacionada com a dimensionalidade dos objetos e itens, uma vez que o formato é definido pela representaçăo geométrica da figura no espaço de dimensốs relevantes.

Pode-se configurar uma figura por sua forma, tamanho e orientação.

\subsubsection{Forma}

As figuras são classificadas, quanto a forma, em regulares e irregulares.

Uma figura é dita regular quando pode ser expressa por poucos parâmetros, como é o caso dos retangulos, paralelípedos e circulos. A grande maioria dos problemas de cortes encontrados na literatura utilizam este tipo de forma. Uma figura regular pode ainda ser do tipo retangular (por exemplo, uma placa retangular e um paralelepípedo), ou não retangular (por exemplo, figura circular).

Problemas de cortes com figuras irregulares não são estudados com frequência, e quando são apresentados, dizem respeito a indústrias especificas, como de couro, tecido ou metal.

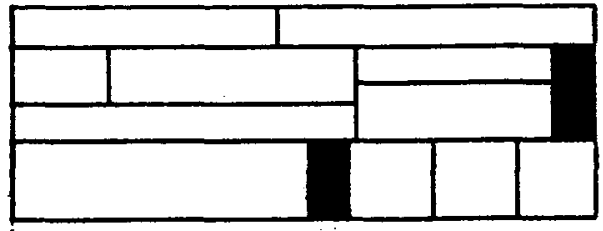

Figuras regulares

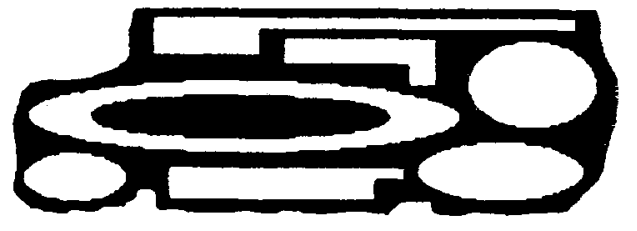

Figuras irregulares

figura 3.2 .1 


\subsubsection{Tamanho}

As figuras de objetos e de itens podem possuir a mesma forma e no entanto podem variar em seus tamanhos. Algumas figuras de tamanhos diferentes podem ser consideradas identicas, pela translação ou pela mudança de escala em torno das dimensões relevantes ao problema.

\section{2 .3 orientação}

Figuras de objetos e itens congruentes, isto é, de mesma forma e tamanho, podem diferir quanto a sua orientação. Pode-se considerar os seguintes casos, em que:

- toda a orientação é permitida: os objetos e itens com figuras congruentes são considerados idênticos;

- a orientação é fixa: objetos e itens de figuras congruentes são diferenciados, exceto aqueles que se tornam idênticos por meio de uma translaçăo;

- a orientação permitida é de no máximo 90 graus: somente são considerados idênticos os objetos e itens de mesma figura.

Exemplo de problema com orientação de objetos e itens pode ser encontrado no corte de uma placa de madeira, no qual as peças retangulares a serem produzidas devam ter as fibras na mesma direção da placa.

Para uma simplificação, figuras de objetos e ítens são chamadas de objetos e 1tens, respectivamente. 


\subsection{Agrupamento}

- problema de cortar objetos a fim de produzir itens pode ser visto como agrupar Itens em objetos. 0 agupamento de Itens em objetos depende fundamentalmente da forma e do número de figuras permitidas.

Pode haver casos em que todos os objetos e itens possuam formas diferentes, e casos em que todos os objetos e itens possuam a mesma forma. Em ambos os casos pode-se ter muitos ou poucos objetos e itens diferentes.

- agrupamento dos objetos pode ocorrer considerando um único objeto, objetos idênticos ou objetos diferentes, agrupamentos estes exemplificados pelos problemas da mochila, empacotamento de bin, além do clássico problema do corte de estoque bidimensional, respectivamente.

- agrupamento de itens ocorre quando existem itens congruentes, muitos itens de muitos formatos diferentes, poucos 1tens de formatos diferentes, muitos itens de relativamente poucos formatos diferentes (não congruentes), exemplificados pelos problemas de carregamento de paletes, empacotamento de bin, carregamento de velculos e problema de corte de estoque.

\section{4 Disponibilidade}

Uma outra caracteristica para os problemas de corte é dada pela disponibilidade de objetos e itens. Ela refere-se aos limites inferiores e superiores de suas quantidades, ao sequênciamento de produção, e ainda à data em que um objeto ou item foi ou será cortado/empacotado. 
Pode-se interpretar o numero de objetos e 1tens a serem considerados como um limite superior de disponibilidade para o processo do corte/empacotamento. Bm alguns casos, o limite inferior é identico ao limite superior, como por exemplo, no problema da Mochila em que um único objeto pode ser cortado em itens. Reciprocamente, no problema do corte de estoque todos os itens requeridos devem ser produzidos.

Limites inferiores e superiores não identicos podem representar uma certa tolerancia minima e máxima, respectivamente. Em muitos casos reais de corte, os clientes aceitam uma tolerancia na produção dos itens requeridos.

Propriedades adicionais são obtidas pelo sequenciamento de produção dos objetos e dos itens, ou ainda quando se determina um tempo de execução. Por exemplo, uma barra de aço pode ser cortada ainda incandescente, ou após um certo periodo de tempo.

Pode-se ainda considerar como restriçôes a data e o tempo em que um objeto ou item foi ou será cortado/empacotado. No carregamento de contêineres, dependendo do produto, é de fundamental importância a separação dos itens por data de vencimento.

3.5. Padrão de Corte

Para a construção de um padräo de corte, pode-se considerar quatro classes de restrições, dadas pela distancia de corte, orientação, frequência de ocorrência e tipo de corte.

3.5.1. Restrição de distancia de corte

Esta restrição é considerada quando se fizer necessária 
uma distancia minima ou maxima entre cortes que dividem os objetos. Como exemplo temos o corte de vidro em que dois cortes năo podem ser produzidos a menos de uma certa distancia.

\subsubsection{Restrição de orientação}

A restrição de orientação pré-determinada de itens ou de objetos devem ser consideradas. O problema do corte de madeira é um exemplo típico de problema com esta restrição. Tal tipo de restrição está melhor definido em 3.2.3.

\subsubsection{Restrição de Frequência}

Esta restrição considera o Indice de frequência de itens no pađrão, especialmente a combinação de itens diferentes. Como exemplo, suponha um problema em que um determinado item tenha um limite de ocorrência em cada padrăo.

\subsubsection{Tipo de Corte}

Os processos de corte geralmente estão restritos a tecnologia dos equipamentos de corte, o que leva a uma restrição dos possiveis padrões de cortes a serem produzidos. 0 tipo de corte utilizado é de fundamental importancia na resolução do problema.

Um grande número de trabalhos encontrados na literatura refere-se a cortes do tipo reto, para objetos e itens na forma retangular ou de blocos. Alguns problemas com cortes curvos săo encontrados em Albano-Sapuppo(1980), Sarin (1983), e Farley (1988). Exemplos ocorrem nas indústrias de tecidos e discos.

Os cortes retos podem ser classificados em ortogonais e 
ndo-ortogonais. Os cortes ortogonais produzem itens a partir do corte paralelo a um dos lados do objeto.

Os cortes ortogonais podem ainda ser classificados como cortes guilhotinados e cortes năo guilhotinados. Os cortes năo guilhotinados são produzidos por equipamentos que, após o inicio do corte, permitem a interrupcăo do processo de corte, antes de alcançar o outro lado do objeto, e a partir dal conduz a um corte perpendicular ao então produzido. Bste tipo de corte pode ser encontrado no corte de chapas metálicas para a indústria automobilistica.

o corte guilhotinado é muito utilizado nas indústrias de papel, móveis e vidro, devido a sua simplicidade e as restrições dos equipamentos de corte utilizados. Neste processo o corte é produzido sobre um objeto, resultando duas partes do objeto, menores e adjacentes. Isto $e$, o corte inicia-se de um lado do objeto e atravessa em linha reta até o lado oposto, de forma ortogonal.

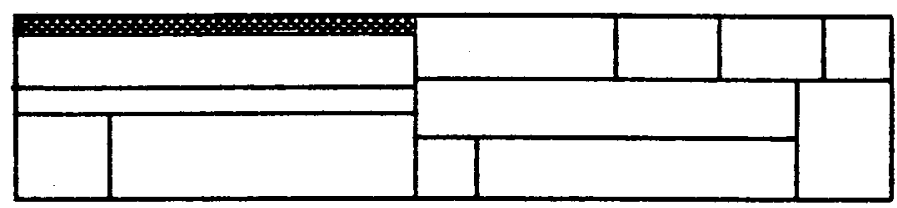

Padrão de corte guilhotinado

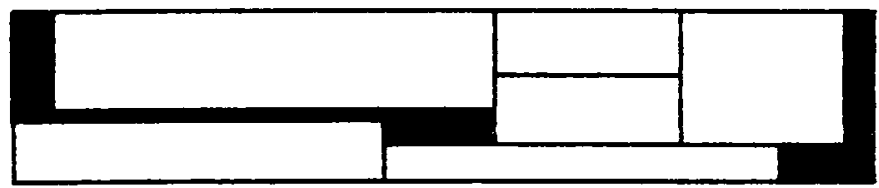

Padrão de corte não guilhotinado

figura 3.5.4.a 
Chama-se de estágio a produçăo de um certo número de cortes guilhotinados numa mesma direço sobre os objetos ou sobre partes dos objetos, resultantes do estágio anterior. Os cortes produzidos em um estágio sáo perpendiculares ao cortes produzidos no estágio antecedente.

Devido a restrição de equipamento, ou do manuseio de objetos intermediários, alguns processos limitam o número máximo de estágios permitidos em um padrão de corte. Por isso, os cortes guilhotinados sáo classificados ainda como cortes estagiados e năo-estagiados.

Os processos com limite $N$ de estágios de corte são denominados cortes $\mathrm{N}$-estagiados.

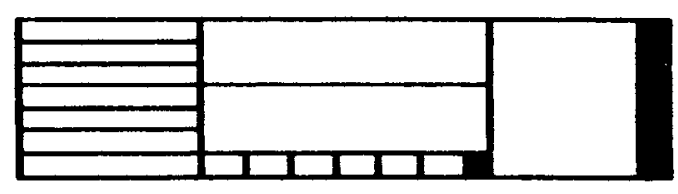

figura 3.5.4.b

Padrão de corte 3 -estagiado

3.6. Forma de Alocação

Um problema de corte de estoque consiste em cortar objetos em estoque a fim de produzir itens encomendados. Este mesmo problema pode ser como uma de maneira de alocar itens em objetos.

Dados objetos e 1tens, pode-se distinguir claramente se uma seleção de itens ou se todos os itens podem ser associados a padróes correspondentes (năo triviais). o problema clássico do Corte de Estoque é exemplo de associação de todos os itens a uma 
seleçáo apropriada de objetos, enquanto que o problema da mochila trabalha com a seleção de itens a serem combinados em um padrăo náo trivial para o objeto.

A alocação de figura de itens em objetos é dada em função de seu formato e número de itens permitidos.

Pode-se ter dois tipos de alocaça de itens requeridos em objetos estocados:

- alocação por seleção de objetos

- alocação por seleção de itens.

\subsubsection{Alocaç̃o por seleção de objetos}

No problema de seleção de objetos, parte-se do princípio de que o conjunto de objetos é suficiente para agrupar todos os itens requeridos. Então, um sub-conjunto de objetos será selecionado para agrupar todos os itens.

3.6.2. Alocação por seleção de itens

Analogamente à seleção de objetos, o problema de seleção de itens consiste em determinar um sub-conjunto de itens para utilizar todos os objetos em estoque.

3.7. Objetivos

Os objetivos dos problemas do corte/empacotamento devem ser expressos, tanto quanto possivel, nas funções objetivos dos modelos de corte/empacotamento. Considera-se um objetivo como um critério a ser maximizado ou minimizado. 
eles destacam-se:

- maximizaçáo da produtividade, que pode ser dada pela maximizaçáo de itens a serem produzidos, a minimizaçáo dos objetos utilizados no atendimento da demanda, a minimizaçăo de perda de material, ou ainda a minimização de perda percentual, todos relacionados com a eficiência técnica do processo de corte.

- minimização do custo ou a maximização do lucro, relacionados com a eficiéncia económica do processo de corte.

3.8. Tipologia de Dyckhoff

Com o intuito de unificar os diferentes usos na literatura e concentrar pesquisas futuras sobre diferentes tipos de problemas de corte/empacotamento, Dyckhoff (1990) apresentou uma tipologia global fundamentada na estrutura logica de tais problemas.

Segundo Dyckhoff a estrutura logica comum aos problemas de corte/empacotamento é determinada:

(i) pela existência de dois grupos básicos cujos elementos definem um conjunto geométrico de formas fixas (figuras dos objetos e itens) em uma ou mais dimensões espaciais:

- o estoque denominado objeto.

- listas de volumes ordenados chamados de 1tens.

(ii) pela geração de padrões, combinações geométricas de itens em objetos. Figuras que ocorrem no padrão, não associadas a itens, são usualmente tratadas como aparas. 
Para a elaboração desta tipologia foram consideradas quatro caracteristicas de classificaçáo dos problemas de corte/ empacotamento, bem como suas divis8es om tipos principais.

A primeira caracteristica considerada foi a dimensto do problema, em virtude de sua complexidade estar envolvida pela geometria das figuras dos objetos e 1tens (cf. 3.1). As dimensóes consideradas foram Unidimensional, Bidimensional, Tridimensional e Multidimensional.

A segunda caracteristica 6 dada pela forma de alocaçăo das figuras dos 1tens e dos objetos, sendo considerada a seleçăo de objetos (V - do alemăo "Veladeproblem"), e a seleçắo de 1tens (B - do alemẩo "Beladeproblem"), ( cf 3.6).

o agrupamento de objetos é a terceira caracteristica, e considera problemas com somente um objeto (0 - do ingles "One"), com todos os objetos idênticos (I - do inglês "Identical") e com todos os objetos de figuras diferentes (D - do ingles "Different"), (cf 3.3).

A quarta caracteristica é dada pelo agrupamento de itens com distinçôes para problemas com todas as figuras congruentes (C - do ingless "Congruent"), com poucas figuras diferentes (F - do inglês "Few"), com muitas figuras diferentes (M - do inglés "Many"), e com muitos itens com relativamente poucas figuras diferentes ( - do inglês "Relatively"), (cf. 3.3).

Os diferentes tipos de problemas de corte/empacotamento podem ser denotados pela quádrupla de símbolos $\alpha / \beta / \gamma / \delta$, correspondentes respectivamente, a dimensão, forma de alocaçăo, agrupamento de objetos, e agrupamento de itens. As quatro caracteristicas, bem como seus principais tipos săo mostrados a seguir: 
a - Dimensăo do problema

1 - Unidimensional

2 - Bidimensional

3 - Tridimensional

N - Multidimensional

B - Forma de alocação

B - Todos os objetos e uma seleção de itens

V - Todos os 1tens e uma seleção de objetos

$\gamma$ - Agrupamento de objetos

o - somente um objeto

I - objetos de figuras idênticas

$D$ - objetos de figuras diferentes

$\delta$ - Agrupamento de 1 tens

$C$ - todos os itens de figuras congruentes

$F$ - poucos itens de figuras diferentes

$M$ - muitos itens de muitas figuras diferentes

$R$ - muitos itens de relativamente poucas figuras diferentes (não congruentes)

Pela combinação das caracteristicas consideradas para a tipologia temos 96 tipos diferentes $(4 \times 2 \times 3 \times 4)$ de problemas de corte/empacotamento.

O problema do corte de estoque bidimensional, comumente estudado, é representado por $2 / V / I / R$, sendo $\alpha=2, \beta=V, \gamma=I$ e $\delta=R$, $O$ que significa problema bidimensional que considera a seleção de objetos de figuras idênticas, para a produção de muitos itens de relativamente poucas figuras diferentes.

A fim de exemplicar a aplicaçâo desta tipologia, a tabela 3.2 associa problemas de cortes/empacotamento encontrados na literatura às suas representações simplificadas, como combinação dos tipos característicos. A ausência de um símbolo na 
quádrupla $\alpha / \beta / \gamma / \delta$ significa que todos os tipos da caracteristica náo apresentada săo possíveis ao problema.

tabela 3.2.

Problemas associados a combinação de tipos

\begin{tabular}{lc}
\hline Problema & Notaçăo \\
\hline Mochila (clássico) & $1 / \mathrm{B} / \mathrm{O} /$ \\
Mochila & $/ \mathrm{B} / \mathrm{O} /$ \\
Corte de Estoque (clássico) & $1 / \mathrm{V} / \mathrm{I} / \mathrm{R}$ \\
Corte de Estoque bidimensional & $2 / \mathrm{V} / \mathrm{I} / \mathrm{R}$ \\
Corte de Estoque & $1 / / /$ \\
& $2 / / /$ \\
Empacotamento de Bins (clássico) & $3 / / /$ \\
Empacotamento de Bins bidimensional & $1 / \mathrm{V} / \mathrm{I} / \mathrm{M}$ \\
Empacotamento de Bins (dual) & $2 / \mathrm{V} / \mathrm{D} / \mathrm{M}$ \\
& $1 / \mathrm{B} / \mathrm{O} / \mathrm{M}$ \\
Carregamento de Paletes & \\
\hline
\end{tabular}

Como pode-se perceber pela notaçăo, os problemas da Mochila (clássico), do Carregamento de Paletes e do Carregamento 
de Conteineres diferem apenas na caracteristica de dimensionalidade, enquanto que os problemas clássicos do Corte de Estoque, do Bmpacotamento de Bins, e do Carregamento de Velculos pertencem a mesma combinaça de tipos quando consideradas somente as três primeiras caracteristicas.

Diferenças entre problemas com mesma notaça podem existir, uma vez que esta notaçåo reduzida determina apenas tipos gerais, cada um deles envolvendo uma variedade de problemas ainda distintos. Como exemplo, os agrupamentos de objetos e itens não diferenciam as formas das figuras regulares das figuras irregulares. Diferenças referem-se as características e tipos não considerados nesta tipologia.

Para uma abrangencia maior dos problemas do corte e empacotamento, esta tipologia poderia ser estendida com a inclusão de novas caracteristicas e tipos, mas Dyckhoff, em virtude da grande variedade de problemas, sugere a utilização de um segundo nivel de classificação para um tipo especifico de problema a ser estudado. 


\section{PROBLEMA DE CORTE BIDIMENSIONAL GUILHOTINADO NĂO-ESTAGIADO E IRRESTRITO}

- problema de corte bidimensional, que será objeto de estudo neste trabalho, consiste em cortar objetos (no caso, uma placa retangular). a fim de produzir itens (peças retangulares), de modo a otimizar uma funçáo objetivo (por exemplo, minimizaç̆o de apara).

Diferentes abordagens e restrições para o problema foram propostas na literatura por vários autores. Pode-se citar os trabalhos de Gilmore e Gomory (1965), Beasley (1985a), Morábito (1989, 1992), e Morábito et al $(1989,1991,1992 a)$, entre outros.

Neste trabalho de dissertação, estudou-se o problema do corte bidimensional guilhotinado não-estagiado e irrestrito $2 / B / O /$, e foram exploradas soluções obtidas pela abordagem em grafo-E/ou com estratégia de busca hibrida "Depth-First/Hill-Climbing", com combinação de várias heurísticas.

\subsection{Descriçắo}

- problema consiste em cortar um objeto retangular de comprimento e largura $(L, w)$, em m itens retangulares $\left(l_{i}, w_{i}\right)$, com valores de utilidades $v_{i}, i=1, \ldots, m$, de modo a maximizar a soma dos valores de utilidade dos ftens cortados.

Um padrão de corte para o problema é dado por $\left(a_{1}, a_{2}, \ldots, a_{m}\right), a_{i} \geq 0$ e inteiro, $i=1, \ldots, m$, se for possivel produzir $a_{i}$ itens do tipo $i$, pelo processo de corte do objeto $(L, W)$.

Um padrẵo de corte dado por $(1,0,3,2,0)$ corresponde a 
produçó de um item do tipo 1, 3 1tens do tipo 3, 2 Itens do tipo 4, e nenhum item dos tipos 2 e 5 .
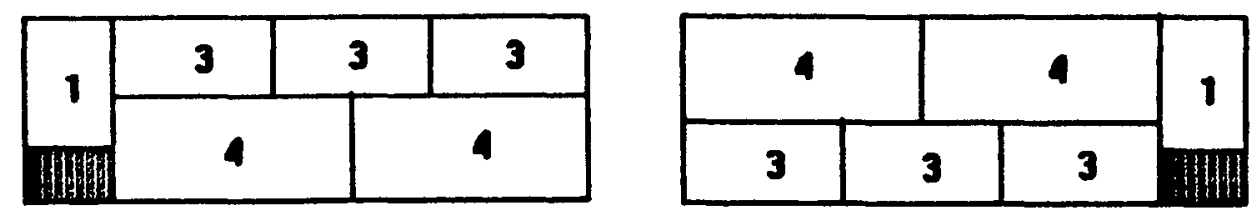

Figura 4.1

Padrôes de cortes dados por $(1,0,3,2,0)$

A figura 4.1 ilustra diferentes padrões de cortes dados pelo mesmo vetor $\left(a_{1}, a_{2}, \ldots, a_{m}\right)$ que são chamados de padrôes de cortes equivalentes.

o problema pode ser assim descrito:

$$
\begin{gathered}
\text { maximizar } f=\sum_{i=1}^{m} v_{i} a_{i} \\
\text { sujeito a que }\left(a_{1}, \ldots, a_{m}\right)
\end{gathered}
$$

seja um padrão de corte bidimensional

guilhotinado para o objeto $(L, W)$

A solução 6tima para o problema (1) é dada pelo padrão de corte de valor utilitário máximo.

Se o problema é restrito à produção máxima de $b_{i}$ quantidades de 1tens $\left(l_{i}, w_{i}\right), i=1, \ldots, m$, entåo o problema consiste em:

$$
\begin{gathered}
\text { maximizar } f=\sum_{i=1}^{m} v_{i} a_{i} \\
\text { sujeito a que }\left(a_{1}, \ldots, a_{m}\right)
\end{gathered}
$$

seja um padrão de corte bidimensional

$$
\text { guilhotinado para o objeto }(L, W)
$$$$
\text { e } \quad 0 \leq a_{i} \leq b_{i}, i=1, \ldots, m
$$ 
Se há demanda a ser atendida na produçăo de 1tens, os problemas (1) ou (2) săo utilizados para a geraçăo de colunas para - programa linear proposto por Gilmore e Gomory e $v_{i}, i=1, \ldots, m$ săo funçốes dos multiplicadores de Lagrange do Método simplex. Para maiores detalhes consultar Gilmore e Gomory (1961,1963, 1965) e Morábito (1989).

Herz (1972) prop6s um método exato, utilizando a estratégia Backtracking. Porém, para problemas grandes esta abordagem torna-se inviável computacionalmente, em virtude de produzir uma explosão combinatorial dos possiveis padróes de corte.

Para problemas grandes, Beasley (1985a), utilizando programação dinamica, sugere uma heuristica para eliminação de alguns possiveis cortes, o que reduz o universo de soluçôes. Esta heurística pode ser aplicada ao procedimento de Herz, bem como às buscas em grafo-E/OU que serăo vistas a seguir, propostas por Morábito et al.(1989,1992), e Morábito e Arenales $(1991,1992 a)$.

\subsection{Redução de cortes possiveis}

A seguir, são definidas regras que reduzem a produção de cortes sobre um retângulo genérico.

\subsubsection{Discretização}

Herz (1972) demonstrou que cortes guilhotinados podem ser representados, sem perda de otimalidade, por combinações lineares nå negativas das dimensôes dos itens, isto é, os possiveis cortes ao longo do comprimento L e largura $W$ podem ser representados pelos elementos dos conjuntos $X$ e $Y$, de possíveis discretizaçôes do objeto $(L, W)$, definidos por: 


$$
x=\left\{x \mid x=\sum_{i=1}^{m} \alpha_{i} \cdot l_{i}, 1 \leq x \leq L-\min \left\{l_{i}\right\}, \alpha_{i} z 0\right. \text { e inteiro, }
$$

e

$$
Y=\left\{y \mid y=\sum_{i=1}^{m} \beta_{i} \cdot w_{i}, 1 \leq y \leq w-\min \left\{w_{i}\right\}, \beta_{i} \geq 0\right. \text { e inteiro, }
$$

o referido autor demonstrou que para qualquer padrão de corte sobre $(L, W)$, existe um outro padrão de corte com valor maior ou igual a este $e$ com todos os cortes em $X$ e $Y$. Isto reduz os exames envolvidos no procedimento de resolução para o processo finito de percorrer $\mathbf{X}$ e $\mathbf{Y}$.

Denomina-se padrăo de corte canônico ao padrăo com todos os cortes em $X$ e $Y$, e padrão de corte homogêneo ao padrão canónico com apenas um tipo de item $\left(l_{i}, w_{i}\right), i=1, \ldots, m$.

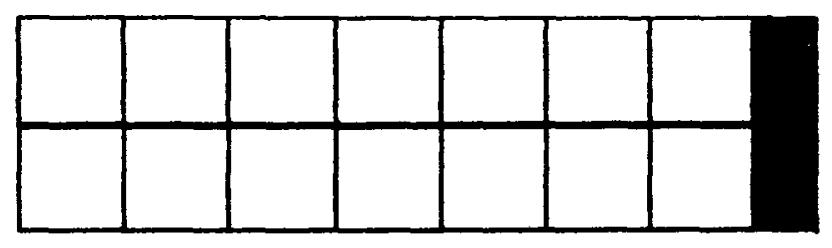

Figura 4.2 .

Padrăo de cortes homogêneos

Dependendo das dimensões do objeto (L,W) e dos 1tens $\left(l_{i}, w_{i}\right), i=1, \ldots, m$, isto $e$, se as razões $L / l_{i}$ e $W / w_{i}$ são muito pequenas, 0 número de elementos de $X$ e pode chegar a milhões, 0 que torna o método exato, para percorrer os conjuntos $X \mathbf{Y}$, inadequado.

Formulas recursivas para a construção dos conjuntos $X$ e 
Y foram propostas por Beasley (1985), e Christofides e Whitlock (1977).

\subsection{Bliminação de padróes equivalentes}

A seguir são definidas algumas regras que podem ser utilizadas no processo de resoluçăo do problema, para a eliminação de ocorrências de padróes de cortes equivalentes.

\subsubsection{Simetria}

Supondo que um objeto $(x, y)$ seja cortado em $x_{1}, x_{1} \in X$, produzindo $\left(x-x_{1}, y\right) e\left(x_{1}, y\right)$. Supondo $x_{2}, x_{2} \in x$ tal que $x_{2}=x-x_{1}$.

Entáo, pode-se produzir um corte em $(x, y)$ dado por $\left(x_{2}, y\right)$ e $\left(x-x_{2}, y\right)$, o que resulta uma duplicação dada por $\left(x-x_{1}, y\right)$ $e\left(x_{2}, y\right)$, onde $x_{2}=x-x_{1}$, conforme figura 4.3.1.

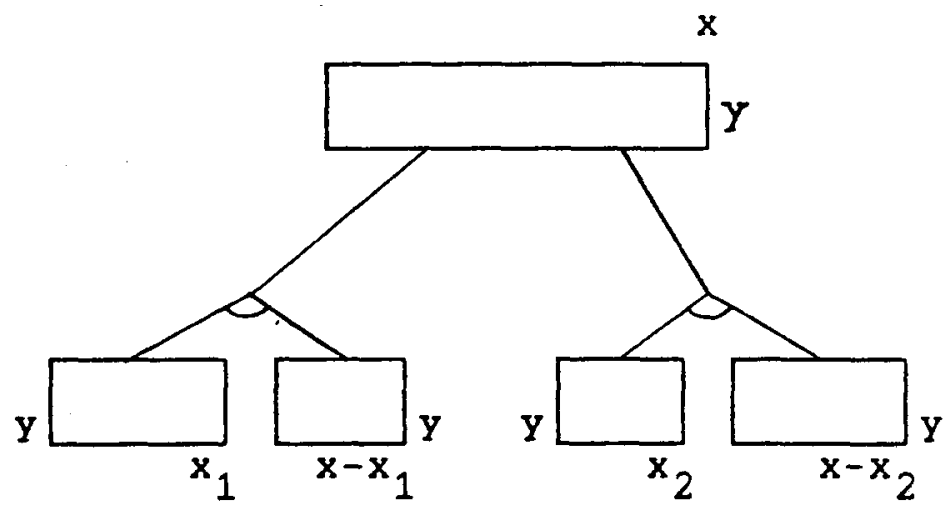

figura 4.3.1. Duplicação de padrões - simetria

Se $x_{2} \notin x$, pode-se tomar o maior elemento de $x$, menor que $x_{2}$, e qualquer padrão obtido pelo corte em $x_{1}$ poderá ser obtido pelo novo corte. 
Isto pode ser evitado, sem perda de otimalidade, simplesmente limitando os cortes sobre um retângulo $(x, y)$, em $\lfloor x / 2\rfloor \odot\lfloor y / 2\rfloor$.

Desta forma, os conjuntos de discretizações podem ser definidos por:

$$
x(x, y)=\left\{x_{1} \mid x_{1}=\sum_{i=1}^{m} \alpha_{i} \cdot l_{i}, 1 \leq x_{1} \leq\lfloor x / 2\rfloor, \alpha_{i} \geq 0 \text { e inteiro }\right\}
$$

e

$$
Y(x, y)=\left\{Y_{1} \mid Y_{1}=\sum_{i=1}^{m} \beta_{i} \cdot w_{i}, 1 \leq y_{1} \leq\lfloor y / 2\rfloor, \beta_{i} z 0 \text { e inteiro }\right\}
$$

onde, $\lfloor x\rfloor$ é o maior inteiro menor ou igual a $x$.

\subsubsection{Ordenação}

Christofides e Whitlock (1977) observaram que os processos de corte sobre um retângulo podem conduzir às construções de padrões idênticos de maneiras diferentes, ocorrendo assim uma duplicação do processo de corte.

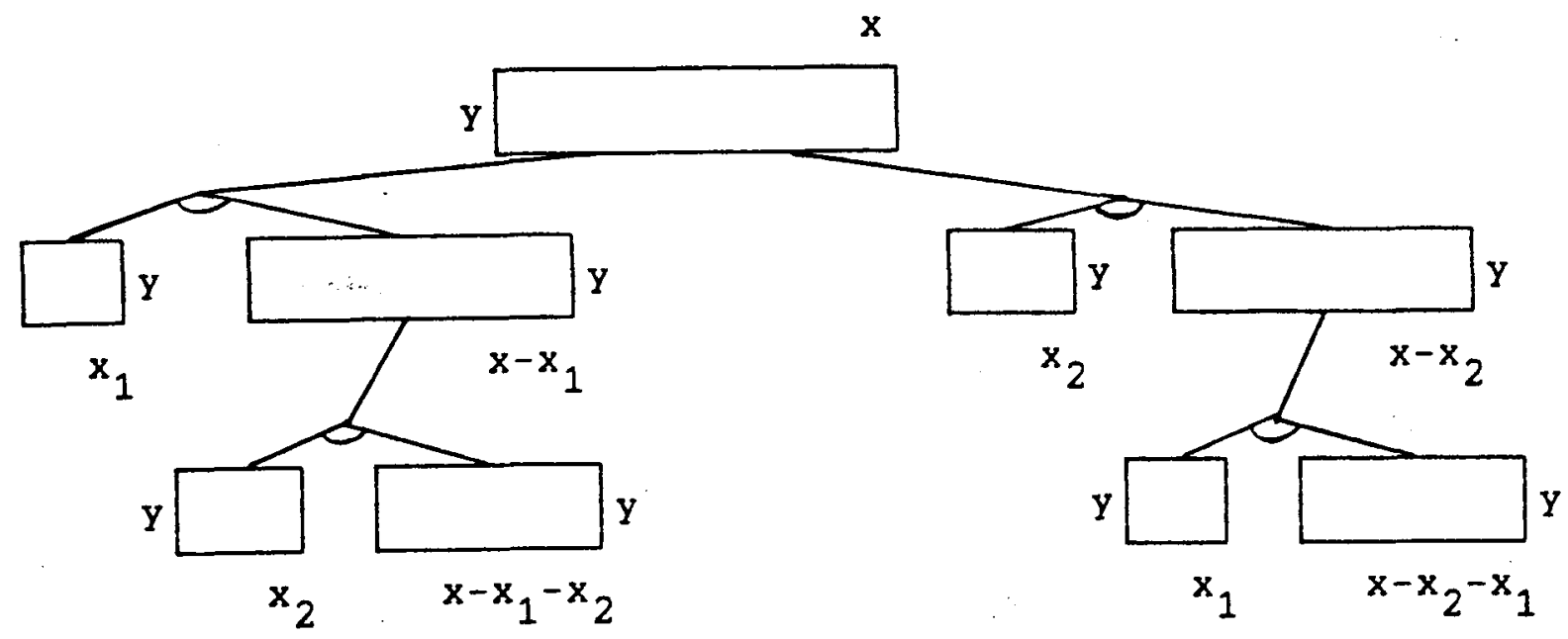

figura 4.3 .2

Duplicação de padróes - ordenação 
Para a nóo duplicaç⿰丿丶⿱⿰㇒一乂 otimalidade, os referidos autores sugeriram que fosse foita uma ordenaçó arbitrária nos cortes. Por exemplo, se um retángulo $(x, y)$ sofre un corte vertical om $x_{1}, x_{1} \in X$, entáo todos os cortes verticais subsequentes sobre $\left(x-x_{1}, y\right)$ e $(x, y)$ devem ser maiores ou iguais a $x_{1}$.

\subsubsection{Exclusão}

Seja $\left(x_{1}, y\right)$ produzido a partir de $(x, y), x_{1} \in X$. A exclusăo da peça $\left(l_{i}, w_{i}\right), i=1, \ldots, m$, pode ser dada, se $w_{i}>y$, uma vez que não é possível produzir $\left(l_{i}, w_{i}\right)$ a partir de $\left(x_{1}, y\right)$, como mostra a figura 4.3.3.

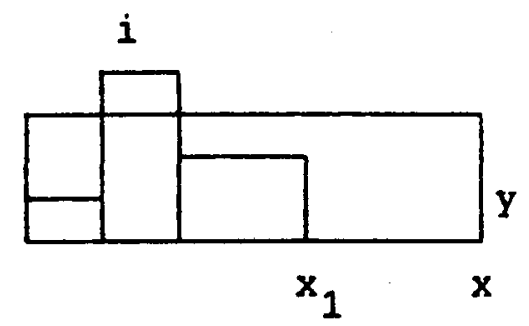

figura 4.3 .3

Exclusão da peça $i\left(w_{i}>y\right)$

Considerando a exclusâo, redefinimos:

$$
\begin{aligned}
x(x, y)=\{ & x_{1} \mid x_{1}=\sum_{i=1}^{m} \alpha_{i}, l_{i}, 1 \leq x_{1} \leq\lfloor x / 2\rfloor,\left(w_{i}>y \Rightarrow \alpha_{i}=0\right), \alpha_{i} \geq 0 \\
& \text { e inteiro, } i=1, \ldots, m\}
\end{aligned}
$$

Supondo $\left(x, y_{1}\right)$ produzido a partir de $(x, y) y_{1} \in Y$, redefine-se analogamente,

$$
\begin{aligned}
Y(x, y)= & \left\{y_{1} \mid y_{1}=\sum_{i=1}^{m} \beta_{i} \cdot w_{i}, 1 \leq y_{1} \leq\lfloor y / 2\rfloor,\left(I_{i}>x \rightarrow \beta_{i}=0\right), \beta_{i} \geq 0\right. \\
& \text { e inteiro, } i=1, \ldots m\}
\end{aligned}
$$




\subsection{Iimitantes Inferiores - 8uperiores}

Suponha um objeto de dimensóes $(x, y)$. Considere,

$$
I(x, y)=\left\{i \mid I_{i} \leq x, w_{i} \leq y, i=1, \ldots, m\right\}
$$

- conjunto de todos os possiveis itens a serem produzidos em $(x, y)$.

Um limitante inferior $\mathscr{L}$ para o valor da soluçăo otima de $(x, y)$ pode ser dado pelo padrăo de corte homogêneo para $(x, y)$, isto é, o valor $\mathscr{L}(x, y)$ corresponde a uma soluçăo trivial que consiste em preencher $(x, y)$ com itens $\left(x_{i}, y_{i}\right), i \in I(x, y)$.

Portanto,

$$
\mathscr{L}(x, y)=\max \left\{v_{i} \cdot\left\lfloor x / I_{i}\right\rfloor \cdot\left\lfloor y / w_{i}\right\rfloor, i \in I(x, y)\right\}
$$

Um limitante superior facilmente computável pode ser dado por relaxar o problema, considerando-se apenas as áreas dos 1tens i cuja soluçầo é dada por:

$$
u(x, y)=(x, y) \cdot \max \left\{v_{i} \cdot /\left(I_{i} \cdot w_{i}\right), i \in I(x, y)\right\}
$$

Seja $V(x, y)$ melhor valor encontrado para o objeto $(x, y)$ até o momento. Suponha que $(x, y)$ possa ser cortado em $x_{1} \epsilon$ $x(x, y)$, de modo a produzir $\left(x_{1}, y\right) \in\left(x-x_{1}, y\right)$.

Se $v(x, y) \geq u\left(x_{1}, y\right)+u\left(x-x_{1}, y\right)$ entăo a geraçăo de nós nắo é necessária. No entanto, se $v(x, y)<\mathscr{L}\left(x_{1}, y\right)+\mathscr{L}\left(x-x_{1}, y\right)$, então $V(x, y)$ é atualizado para o valor de $\mathscr{L}\left(x_{1}, y\right)+\mathscr{L}\left(x-x_{1}, y\right)$. 


\subsection{Heuristicas}

Pode-se ainda, utilizar heuristicas para diminuir o número de cortes sobre um objeto (retangulo) a serem considerados.

\subsubsection{Discretização de Beasley}

Para problemas em que os conjuntos $x$ e $y$ de discretizações sobre o objeto $(L, W)$ são muito grandes, Beasley (1985a) propós uma heuristica que limita o número de elementos em $\mathbf{X} \mathbf{Y}$.

Seja $M$ um limitante da cardinalidade de $X$, isto é $|X| \leq M$ (M limitado pela capacidade computacional). O procedimento heuristico para redefiniçăo de $X$ é dado por:

(1) Seja $\mathbb{D}=\{1,2, \ldots m\}$, o conjunto que representa as $m$ peças demandadas.

(2) $x=\left\{x \mid x=\sum_{i \in D} \alpha_{i} \cdot l_{i}, 1 \leq x \leq L-\min _{j \in \mathbb{D}}\left\{l_{j}, \alpha_{i} z 0\right.\right.$ e inteiro\}

(3) $\operatorname{se}|x|>M$ então

$I_{j}=\min \left\{I_{i}, i \in \mathbb{D}\right\}$

$\mathbb{D}=\mathbb{D}-[j]$

vá para (2)

Senão

Saia com o $X$ atual.

Este procedimento elimina a cada passo o item $i$ com menor comprimento $l_{i}$ do conjunto $D$, até que o conjunto $x$ tenha um certo número de elementos aceitável para a resolução do problema.

Analogamente, redefine-se o conjunto $Y$. 
Com a consideraclo desta heuristica no procedimento de resoluçăo do problema, năo se pode garantir que a soluçăo encontrada seja a soluçóo ótima.

\subsubsection{Limitantes heuristicos}

Limitantes heuristicos foram propostas por Morabito et al (1992) para eliminaçăo de cortes, em funçăo dos limitantes inferiores e superiores discutidos em 4.4, da seguinte maneira:

Sejam $\alpha$ e parametros previamente definidos.

Se,

ou

$$
\alpha\left(u\left(x_{1}, y\right)+U\left(x-x_{1}, y\right)\right) \leq \mathscr{L}(x, y)
$$

$$
\beta\left(\mathscr{L}\left(x_{1}, y\right)+\mathscr{L}\left(x-x_{1}, y\right)\right) \leq \mathscr{L}(x, y)
$$

então, este corte sobre $(x, y)$ nâo precisa ser produzido. Isto é, se $\left(U\left(x_{1}, y\right)+U\left(x-x_{1}, y\right)\right)$ ou se $\left(\mathscr{L}\left(x_{1}, y\right)+\mathscr{y}\left(x-x_{1}, y\right)\right)$ nấo for muito maior do que $\mathscr{L}(x, y)$, este pode ser um indicativo de que este corte sobre $(X, y)$ năo é tăo promissor, o que implica em descartá-10.

\subsection{Fórmula recursiva de Beasley}

A fórmula recursiva de Beasley (1985a), baseado em programaçấo dinamica para encontrar a soluçâo otima do problema bidimensional guilhotinado nắo-estagiado e irrestrito, é dada por:

Sejam

$$
F(x, y) \text { : valor da funçăo objetivo de }(x, y)
$$

e 


$$
\left.H(x, y)=\max \left\{v_{i} \cdot\lfloor x /\rfloor_{i}\right\rfloor \cdot\left\lfloor y / w_{i}\right\rfloor, i=1, \ldots, m\right\}:
$$

o melhor padråo de corte homogéneo para $(x, y)$.

Bnt8o,

$$
\begin{aligned}
& F(x, 0)=F(0, y)=0 \quad V x, V y \\
& F(x, y)=\max \{H(x, y) ; \\
&\left\{F\left(x_{1}, y\right)+F\left(\left\lfloor x-x_{1}\right\rfloor, y\right), x_{1} \in X, x_{1} \leq x-1\right\} ; \\
&\left.\left\{F\left(x, y_{1}\right)+F\left(x,\left\lfloor y-y_{1}\right\rfloor_{Y}\right), y_{1} \in Y, y_{1} \leq y-1\right\}\right\} \\
& x \in X \cup\{L\}, y \in Y u\{w\}
\end{aligned}
$$

onde,

$$
\begin{aligned}
& \lfloor x\rfloor_{X}=\operatorname{máx}\left\{0, x_{1} \mid x_{1} \leq x, x_{1} \in X\right\} \\
& \lfloor y\rfloor_{Y}=\operatorname{máx}\left\{0, y_{1} \mid y_{1} \leq y, y_{1} \in Y\right\}
\end{aligned}
$$

A deficiência do método reside no fato de que se os conjuntos $X$ e $Y$, a serem considerados na aplicação do procedimento recursivo, năo forem completamente gerados, isto é, forem limitados por um certo valor $M$ (capacidade de máquina), a solução ótima pode não estar representada em $X X Y$, o que conduzirá a uma solução quase ótima.

Morábito et al (1992) mostraram que este procedimento, com a redução de $X$ e $Y$, pode perder soluções simples, encontradas por exemplo pelo algoritmo 2-estagiado.

\subsection{Formula de Christofides e Whitlock}

Christofides e Whitlock (1977) propuseram uma formula recursiva para a construçăo de $X$ e $Y$ em qualquer retângulo $(X, Y) E$ $(L, W)$. Inicialmente, ela é aplicada apenas em (L,W) e depois os conjuntos $X$ e $Y$ são construidos para qualquer $(X, Y) \in(L, W)$. 
supondo-se, sem perda de generalidade, que as in pecas estáo na ordem năo-decrescente $l_{1} \leq l_{2} \ldots 1_{m}$.

Bntåo,

$$
\begin{aligned}
F_{i}\left(x_{1}\right)=\min & \left\{F_{i-1}\left(x_{1}\right) ;\right. \\
& \left.\max \left\{w_{i} ; \min \left\{F_{i}\left(x_{1}-\rho l_{i}\right), 1 \leq \rho \leq\left\lfloor x_{1} / I_{i}\right\rfloor \text { e } \rho \text { inteiro }\right\}\right\}\right\} \\
& 1_{i} \leq x_{1} \leq\lfloor L / 2\rfloor \\
& F_{i}\left(x_{1}\right)=F_{i-1}\left(x_{1}\right), x_{1}<1_{i}
\end{aligned}
$$

onde,

$$
\begin{aligned}
& F_{i}(0)=0, i=0, \ldots, m \\
& F_{0}\left(x_{1}\right)=\infty, x_{1}=1, \ldots,\lfloor L / 2\rfloor
\end{aligned}
$$

$\lfloor x\rfloor$ : maior inteiro menor ou igual a $x$

Seja $F_{i}\left(x_{1}\right)$ finito, correspondente a minima entre as máximas larguras dos itens (peças) $1,2, \ldots, i$ que combinados os seus comprimentos produzem $x_{1}$, isto é,

$$
\begin{gathered}
F_{i}\left(x_{1}\right)=\min \left\{F_{i-1}\left(x_{1}\right) ; \max \left\{w_{j} \mid \alpha_{j}>0, j=1, \ldots, i\right\}\right\} \\
0 \text { conjunto } x(x, y) \text { pode ser construido para qualquer } \\
(x, y) \text {, determinado } F_{m}\left(x_{1}\right) . \text { Se } F_{m}\left(x_{1}\right) \leq y \text { então } x_{1} \in X(x, y) .
\end{gathered}
$$

Assim, o conjunto de discretizaçồes $X$ é dađo por:

$$
\begin{aligned}
x(x, y)= & \left\{x_{1} \mid x_{1}=\sum_{i=1}^{m} \alpha_{i} \cdot l_{i}, 1 \leq x_{1} \leq\lfloor x / 2\rfloor \text { e } F_{m}\left(x_{1}\right) \leq y, \alpha_{i} \geq 0\right. \\
& \text { e inteiro }\}
\end{aligned}
$$

Analogamente, uma funçẩo $G_{i}\left(y_{i}\right)$ similar a $F_{i}\left(x_{1}\right)$ pode ser dada por:

$$
\begin{aligned}
y(x, y)= & \left\{y_{1} \mid y_{1}=\sum_{i=1}^{m} \beta_{i} \cdot w_{i}, 1 \leq y_{1} \leq\lfloor y / 2\rfloor e G_{m}\left(y_{1}\right) \leq x, \beta_{i} \geq 0\right. \\
& \text { e inteiro\} }
\end{aligned}
$$




\section{REPRESENTAÇÃO EM GRAFO-E/OU}

A utilizaçáo de grafo-B/OU para representaço de problemas, bem como a utilizaçóo de estratégias de buscas om grafo para a resoluçăo de problemas, são métodos e técnicas utilizados na área de Inteligencia Artificial.

A seguir, introduzida uma abordagem em grafo-B/OU, para representar o melhor padráo de corte para o problema bidimensional guilhotinado náo-estagiado e irrestrito, como caminhos completos do grafo.

\subsection{Conceitos básicos}

Supondo o problema de cortar um objeto, no presente caso uma placa retangular ( $L, W)$, com a finalidade de produzir 1 tens, peças retangulares $\left(l_{i}, w_{i}\right)$. A solução para tal problema é dada pelo padräo de corte guilhotinado que maximizar a soma das áreas das peças cortadas.

- processo de corte guilhotinado sobre a placa produz exatamente dois novos retangulos, que devem ser cortados até que sejam obtidas as peças requeridas. A figura 5.1 .a ilustra uma sequência de corte sobre uma placa $A=(L, W)$.

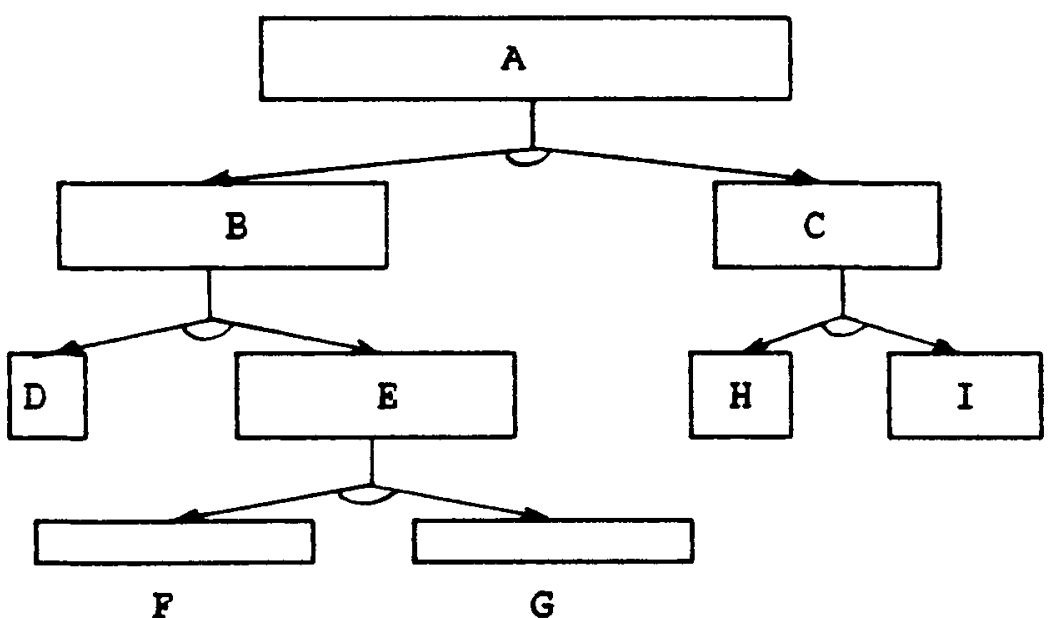

figura 5.1.a - Sequência de cortes sobre A 
Inicialmente, um corte guilhotinado vertical aplicado sobre $A=(L, W)$ produziu os retangulos B $\bullet$ C. supondo B - C retangulos intermediarios que năo representam as peças a serem produzidas, entăo um processo de corte sobre eles foi aplicado, independentemente. Aplicando um corte vertical sobre B, foram produzidos D e $\mathrm{E}$, sendo que D representa uma peça a ser produzida, e E um retangulo a ser cortado. Um corte horizontal foi aplicado em $E$, e dois retangulos $F$ e que representam peças a serem produzidas foram gerados. Finalmente, um corte vertical foi executado em C, produzindo os retangulos finais H $\Theta I$.

A sequéncia de cortes sobre A produziu o seguinte padráo de corte para o problema:

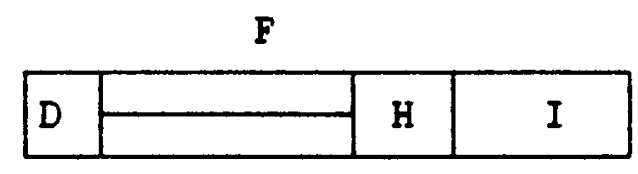

G

figura $5.1 . b$

Padrão de cortes sobre A

Denomina-se nó um retângulo a ser cortado, isto é, um problema a ser resolvido; no inicial ou no raiz a placa (L,W) a ser cortada, ou o problema original a ser resolvido; nos intermediários aos retangulos intermediarios a serem cortados; $\theta$ nós finais ou nós folhas aos retångulos que representam peças $\left(I_{i}, w_{i}\right)$ a serem produzidas, ou uma apara resultante do processo de corte. 
$A$ aço de cortar un determinado nó 6 representada por um arco, denominado arco-B, que interliga o no cortado com seus sucessores.

o conjunto de n6s a arcos denominado grafo. Um grafo 6 dito direcionado ou digrafo quando os arcos apontam para os nós, mostrando a relação existente entre os nós. A figura 5.1.a ilustra um grafo direcionado, com nó inicial $A, n 6 s$ intermediários $B, C$, $B$, O nós finais $D, F, G, H \in I$.

Se um arco direcionado do nó $x$ para o nó $x_{1}$, entáo 0 nó $x_{1}$ chamado sucessor ou filbo de $x$ e nó $x$ chamado pai de $x_{1}$.

Além disso, se um grafo tiver alternativas de decomposiçăo dos problemas, esta representaçăo é indicada por arcos-ou.

Chamou-se de grafo-B/OU a estrutura que contém arcos do tipo $E$ e arcos do tipo ou. A figura 5.1.a representa um grafo-E/OU com apenas uma opção de corte para o nó $A$. O número de arcos-oU que emanam de um nó corresponde ao grau de ramificaçăo deste nó.

Nota-se que a aplicação de um corte em um nó decompồe este nó em dois novos nós sucessores. Portanto, a solução de um nó é dada pela uniăo das soluçôes de seus nós sucessores. Bste processo de decomposição é considerado pela área de Inteligência Artificial como Redução do Problema, e a estrutura de representaçăo mais comumente utilizada vem sendo o grafo-E/OU.

A sequência de $\operatorname{arcos} a_{1} a_{2} \ldots a_{k}$, que interliga seus respectivos nós sucessivamente, dita caminho com comprimento $k$, $k>1$, e sua representação é um subgrafo-B/OU. Num grafo-B/OU, um caminho é dado pela escolha de um único arco-B, e a partir de cada sucessor escolhe-se novamente um único arco-B. O caminho que 
começa no nó inicial e termina em nós finais é denominado caminho completo. Note que a figura 5.1.a ilustra um caminho completo para A.

- valor de um caminho completo é dado pela soma dos valores dos nós, sendo que se um nó final representa uma peça $\left(l_{i}, w_{i}\right)$ a ser produzida, entáo, o seu valor é $v_{i}$. Senão o valor é zero.

Pode-se dizer que para todo padrão de corte existe um caminho completo no grafo-E/OU correspondente. Então, o problema de encontrar o melhor padrăo de corte consiste em buscar no grafo-E/OU o melhor caminho completo, isto é, o caminho completo de maior valor, no caso de maximização.

A profundidade de um nó no grafo é dada pela profundidade de seu nó pai somado com um, sendo que a profundidade do nó inicial é zero (por exemplo, na figura 5.1.a a profundidade do nó $F$ é 3 ), enquanto que a profundidade de um grafo é dada pelo valor da profundidade do no mais distante do nó raiz.

Denomina-se árvore-E/OU ao grafo-E/OU cujos nós têm um único pai, exceto o nó inicial. A figura 5.1.a, representa uma árvore-E/OU.

\subsection{Estratégias de Busca}

Um grafo pode ser representado implicita ou explicitamente, porém a representação explicita para grafos com muitos nós é praticamente inviável. Na tentativa de sanar este problema, usa-se uma busca no grafo-E/OU que consiste em explicitar (gerar) apenas uma parte do grafo, o suficiente para exibir pelo menos um caminho completo. 
Pearl (1984), ao se referir ao processo de busca, denomina nó expandido ao nó com todos os seus sucessores já gerados, e no explorado ao no com apenas alguns sucessores gerados. Durante a busca pode-se ter:

- nós expandidos,

- nós explorados, mas năo expandidos,

- nós gerados, mas nâo explorados,

- nós ainda não gerados.

Uma estratégia de busca consiste em gerar nós, a partir do nó inicial, utilizando-se regras, de maneira a obter uma solução para o problema.

As regras básicas de geração de nós podem ser classificadas em regras informadas, que escolhem um no pelo uso de informaçôes colhetadas durante o processo de busca, e regras năo informadas, que determinam a priori a ordem de escolha do nó a ser resolvido.

Como exemplos de estratégias que utilizam regras informadas tem-se os procedimentos de busca "Hill-Climbing" e "Best-First", enquanto que o "Depth-First" e "Breadth-First" são exemplos de estratégias com regras nâo-informadas.

5.2.1. Busca em Largura-primeiro - "Breadth-First search"

A busca em largura-primeiro, consiste em expandir os nós mais próximos ao nó inicial. Isto é, expandir os nós na ordem em que foram gerados.

5.2.2 Busca em Profundidade-primeiro - "Depth-First search"

A busca em profundidade-primeiro consiste em expandir primeiro os nós mais recentemente gerados, isto é, uma vez 
expandido o no inicial é escolhido o primeiro nó filho (por convençăo $\circ$ mais a esquerda), e este é expandido, ignorando momentaneamente os outros nós gerados. Segue-se desta maneira até encontrar uma solução para o problema ou até encontrar um nó final. Neste caso ocorre um retorno ao nó mais recentemente gerado, e novamente é escolhido o no mais a esquerda e o processo continua analogamente.

\section{"Backtracking"}

Uma importante variação da busca em profundidade-primeiro é a estratégia backtracking, que ao invés de expandir, consiste em explorar os nós mais recentemente gerados.

5.2.3. Busca da Escalada - "Hill-Climbing search"

A busca da escalada emprega a estratégia de tentar obter a solução ótima pela escolha dos nós que parecem ser mais promissores, isto é, depois de expandido um no, é escolhido o melhor nó dentre todos os seus sucessores para ser expandido, descartando todos os demais.

5.2.4. Busca pelo Melhor-primeiro - "Best-First search"

A estratégia de busca pelo melhor-primeiro examina, a cada passo do processo, todos os nós gerados até o momento e expande $\circ$ mais promissor. Este método combina as vantagens da busca em Profundidade-primeiro e da busca em Largura-primeiro.

Para um estudo mais aprofundado sobre os procedimentos de busca, geralmente utilizados em Inteligência Artificial, consultar Kvicta (1988), Nilsson (1971), Pearl (1984), Rich (1983), e Shiray e Tsujii (1988). 
Segundo Pearl (1984), caracterizando-se as estratogias de busca"Depth-First - Backtracking" (DP), "Best-Pirst"(BP) "Hill-Climbing" (HC) ao longo das dimensôes: - Recuperaço (R): grau de retomada a novos caminhos previamente
suspensos,

- Alcance (A): número de alternativas consideradas em cada nota-se que estas se encontram em tres pontos extremos de uma regiáo continua de técnicas de busca, como mostra a figura 5.2 .5 .

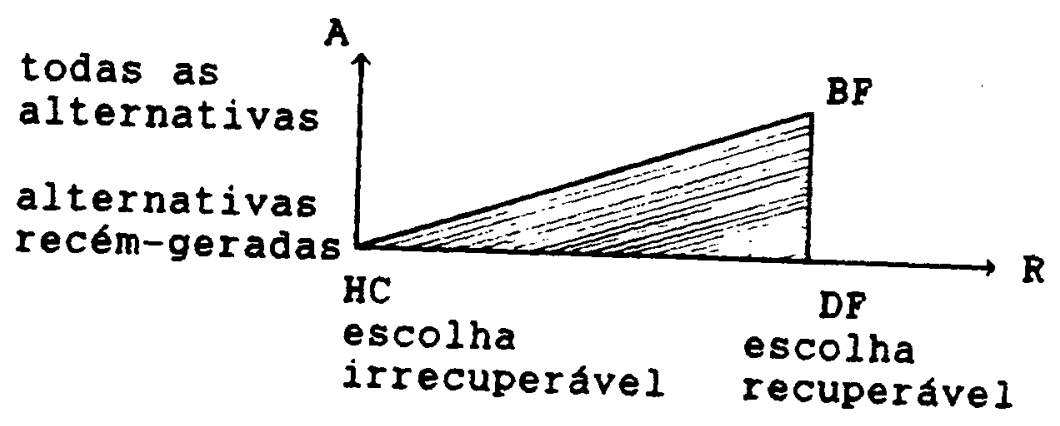

Figura 5.2 .5

Bstratégias de buscas hibridas

Ao longo da dimensăo de Recuperação encontra-se em um extremo o "Hill-climbing", que não permite a recuperaçáo de caminhos suspensos, e num outro extremo tem-se o "Depth-first backtracking" e "Best-first", em que as escolhas dos caminhos são
provisorias.

Considerando a dimensão de Alcance, encontra-se no extremo de caminhos recém gerados os métodos "Hill-Climbing" e "Depth-First - Backtracking", e no outro extremo o "Best-First" que examina a cada escolha a totalidade de caminhos disponiveis. 
A area hachurada representa as combinaçóes possiveis de caracteristicas destas tres estratogias de buscas. Tais combinaçóes slóo denominadas estratógias de buscas hlbridas.

Pode-se dizer que as estratogias de busca DF - BF encontram a soluçóo otima para um problema, se a soluçăo existir. Porém, dependendo do problema, DF pode consumir muito tempo computacional e BP pode consumir muita memória. Ja 0 HC pode consumir pouca memoria e pouco tempo, por ́m năo pode garantir que a solução otima será encontrada.

Preocupados com o fato de que problemas de cortes possam conduzir a uma resoluçăo com tempo computacional elevado e muito consumo de memória, Morábito et al (1989, 1991, 1992, 1992a), propuseram um algoritmo de busca hibrida, que combina as estratégias de busca "Hill-Climbing" e "Depth-Pirst Backtracking", denominado HC_DF. Tal procedimento utiliza pouca memória e permite encontrar rapidamente uma boa solução para um problema de corte bidimensional guilhotinado năo-estagiado e irrestrito, isto é, o melhor padrăo de corte.

Encontrar o melhor padrăo de corte para o problema consiste em gerar uma parte de um grafo-B/OU, até que o nó inicial seja resolvido. Diz-se que um nó $x$ está resolvido se:

(i) for um nó final;

(ii) todos os sucessores de $x$ estiverem resolvidos;

( $i i i$ ) a condiçắo $\mathscr{L}(x)=U(x)$ for satisfeita (Seçäo 4.4 ).

Pearl (1974) e Nilsson (1971) apresentaram definiçôes diferentes para o nó resolvido, porém esta é a mais adequada para descrever o algoritmo adiante.

Para uma simplificaçâo, utiliza-se árvore-B/OU ao invés de grafo-B/OU, pois são mais simples de serem geradas, uma vez que cada nó recém gerado é único, isto 6 , supöe-se que ele năo tenha sido gerado anteriormente e que nåo será gerado novamente. 
De maneira geral, exibe-se a seguir os algoritmos de busca em grafo-E/OU (árvore), utilizando as estratégias "Depth-First - Backtracking" (DF) e HC_DF, com profundidade limite (Depth) a priori definida.

\section{Algoritmo DF}

Coloque o nó inicial, denominado $s$, em OPEN.

Enquanto OPEN não estiver vazio e s não estiver resolvido, faça:

Examine o nó do topo de OPEN e chame-o de $\left(x_{1}, x_{2}\right)$.

Se a profundidade de $\left(x_{1}, x_{2}\right)$ for igual a depth, entáo: remova $\left(x_{1}, x_{2}\right)$ de OPEN.

Senăo,

Se $x_{1}$ năo estiver resolvido, então:

Se $x_{1} j a ́$ estiver expandido, então: rotule $x_{1}$ resolvido.

Senão,

gere um novo par de sucessores de $x_{1}$. Chame-o $\left(x_{1}{ }^{\prime}, x_{2}{ }^{\prime}\right)$. Coloque-o no topo de OPEN.

Disponha um ponteiro de $\left(x_{1}^{\prime}, x_{2}^{\prime}\right)$ para $\left(x_{1}, x_{2}\right)$ senẫo, Verifique se $x_{1}^{\prime}$ e $x_{2}^{\prime}$ estão resolvidos.

Se $x_{2}$ não estiver resolvido e se a melhor solução encontrada até o momento para o pai de $\left(x_{1}, x_{2}\right)$ puder ser superada, então:

Se $x_{2}$ já estiver expandido, então: rotule $x_{2}$ resolvido.

Senão,

Gere um novo par de sucessores de $x_{2}$ Chame-o $\left(x_{1}{ }^{\prime}, x_{2}{ }^{\prime}\right)$. Coloque-o no topo de OPEN. Disponha um ponteiro de $\left(x_{1}{ }^{\prime}, x_{2}{ }^{\prime}\right)$ para $\left(x_{1}, x_{2}\right)$. verifique se $x_{1}{ }^{\prime}$ e $x_{2}{ }^{\prime}$ estẳo resolvidos.

Senão,

Atualize o pai de $\left(x_{1}, x_{2}\right)$ com a melhor solução encontrada até o momento. Remova $\left(x_{1}, x_{2}\right)$ de OPEN. 
Note que OPEN é uma lista que contém os nós explorados, mas năo expandidos, e os nós gerados, mas năo explorados.

\section{Algoritmo HC_DF}

Defina a profundidade limite (depth) para as árvores-E/OU a serem geradas.

Seja ROOT uma lista contendo inicialmente apenas o nó inicial. Enquanto ROOT não estiver vazia, faça:

Seja $s$ o primeiro no de ROOT.

Gere uma árvore-E/OU a partir do nó $s$, sem ultrapassar a depth. Utilize para isso o algoritmo "Depth-First Backtracking" (DF).

Retire $s$ de ROOT.

Escolha o caminho mais valioso (sub-árvore-E/OU) a partir de $s$, e elimine os demais (estratégia "Hill-Climbing" - HC).

Se existem nós neste caminho com profundidade igual a depth, e que năo sejam nós finais, então:

Coloque-os em ROOT.

- algoritmo HC_DF será aplicado para resoluçâo do problema de corte bidimensional guilhotinado não-estagiado e irrestrito. o processo de busca termina quando o nó inicial, representando a placa $(L, W)$, estiver resolvido.

Note que cada caminho escolhido a partir de $s$ corresponde a um sub-caminho do caminho completo, desde 0 nó inicial até os nós finais. A estratégia "Hill-Climbing" não garante que o caminho completo de maior valor, ou melhor, o padrão de corte com maior valor, seja encontrado para o problema.

Para a eliminação de cortes e exclusão de itens durante o processo de busca, pode-se ainda utilizar regras apresentadas no 
capitulo 4, tais como:

- Discretizaçáo,

- Simetria, exclusăo e ordenaçăo de 1tens, e

- Limitantes superiores e inferiores.

e ainda heuristicas:

- Discretização de Beasley, e

- Limitantes heuristicos.

A seguir, avalia-se a heuristica de discretizaçōes de Beasley (1985a) para a geração de possiveis cortes, comparando-a com um processo de geraçăo aleatório dos conjuntos de discretizaçốes. Além disto, apresenta-se uma proposta de combinação da regra de simetria com a heurística de Beasley (op. cit), e compara-se os resultados obtidos por esta combinação com os resultados apresentados na literatura, e que não consideram tal combinação. 


\section{RESULTADOS COMPUTACIONAIS}

Os exemplos apresentados a seguir foram executados em microcomputador AT 286 compativel com IBM PC, sem co-processador aritmético, com clock de $16 \mathrm{MHz}$ e 1 Mbyte de RAM.

Para mostrar a performance das heuristicas discutidas no capitulo 5, foram utilizados problemas de cortes bidimensionais guilhotinados não-estagiados e irrestritos encontrados na literatura.

\subsection{Discretização}

A heuristica proposta por Beasley (capitulo 4, seçôes 2.1 e 5.1) será objeto de atenção especial inicialmente. Esta heuristica seleciona um subconjunto do conjunto de discretizações, segundo a regra discutida anteriormente.

A intenção é verificar se o subconjunto escolhido é de fato "inteligente", isto é, se a solução obtida por cortes neste subconjunto é melhor que a solução obtida por um subconjunto aleatório de mesma cardinalidade.

Para determinação dos resultados foi utilizado o
procedimento recursivo para percorrer os conjuntos de
discretizações, proposto por Morábito (1989).

Escolheu-se o exemplo proposto por Beasley (1985, p.305) - tabela 6.1 para ilustrar o desempenho de sua heuristica, para os conjuntos de discretizações ao longo das dimensões da placa. Este exemplo deriva de um problema prático de cortar um placa retangular de dimensões $L=3000$ e $W=3000$, a fim de produzir peças especificadas. 0 valor de utilidade de cada peça $\left(1_{i}, w_{i}\right)$ é dado pelo valor $v_{i}=l_{i} \cdot w_{i}$, que corresponde a área da peça. A função 
objetivo é dada pela maximizaçăo da area das peças produzidas.

Tabela 6.1.

Exemplo apresentado por Beasley

$\begin{array}{lcccccc}(L, W) & (3000,3000) & \left(l_{i}, w_{i}\right) i=1, \ldots 32 \\ (365,185) & (520,205) & (555,496) & (572,1390) & (690,447) \\ (378,200) & (520,350) & (555,659) & (572,1490) & (949,445) \\ (410,165) & (540,530) & (567,473) & (572,1590) & (949,478) \\ (425,148) & (549,1413) & (572,592) & (572,1690) & (970,463) \\ (425,296) & (549,1882) & (572,975) & (572,1890) & \\ (439,116) & (553,496) & (572,1172) & (610,625) & \\ (464,1006) & (555,755) & (572,1575) & (660,490) & \end{array}$

O gráfico 6.1 ilustra o desempenho da heuristica versus uma escolha aleatoria dos pontos de discretizações, para um universo de 30 execuções do problema, ordenadas em ordem ascendentes dos valores obtidos.

Neatória: 8.607 .880 Beasley: 8.863 .620

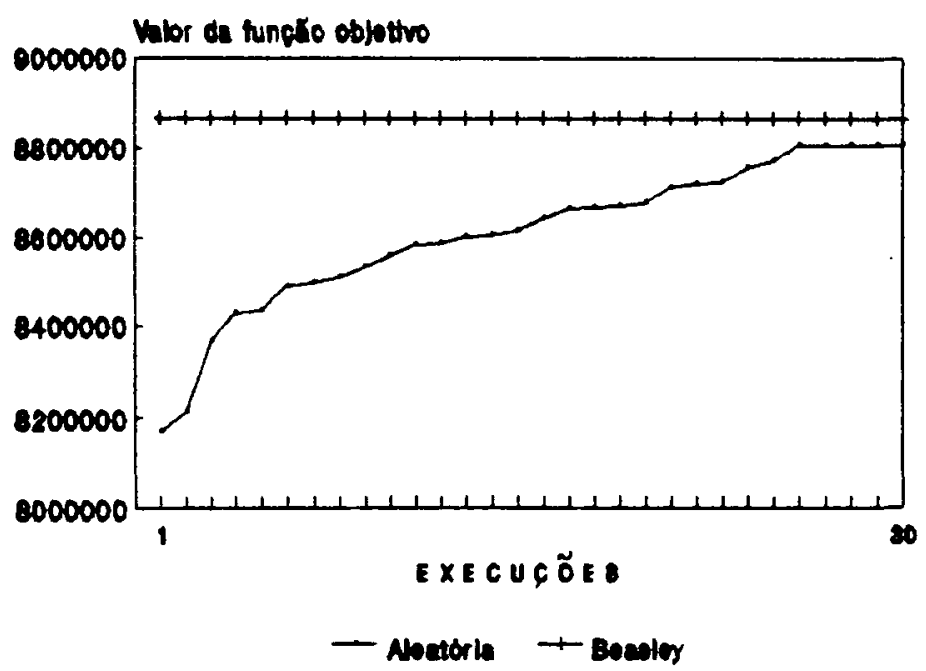

gráfico 6.1.

Heuristica de Beasley x Bscolha aleatoria 
Percebe-se que o resultado obtido por Beasley é significativamente melhor do que a média dos resultados obtidos pela escolha aleatória dos pontos de discretizaçoses.

- gráfico 6.2. ilustra o desempenho da heuristica de Beasley versus uma escolha aleatoria restrita ao intervalo de (1000,3000). Tal intervalo foi escolhido pois possuia a maior concentração dos pontos utilizados na heuristica de Beasley. Novamente, ordenou-se os resultados para uma melhor visualização.

Neatoria: 8.815 .790 Beasley: $\mathbf{8 . 8 6 3 . 6 2 0}$

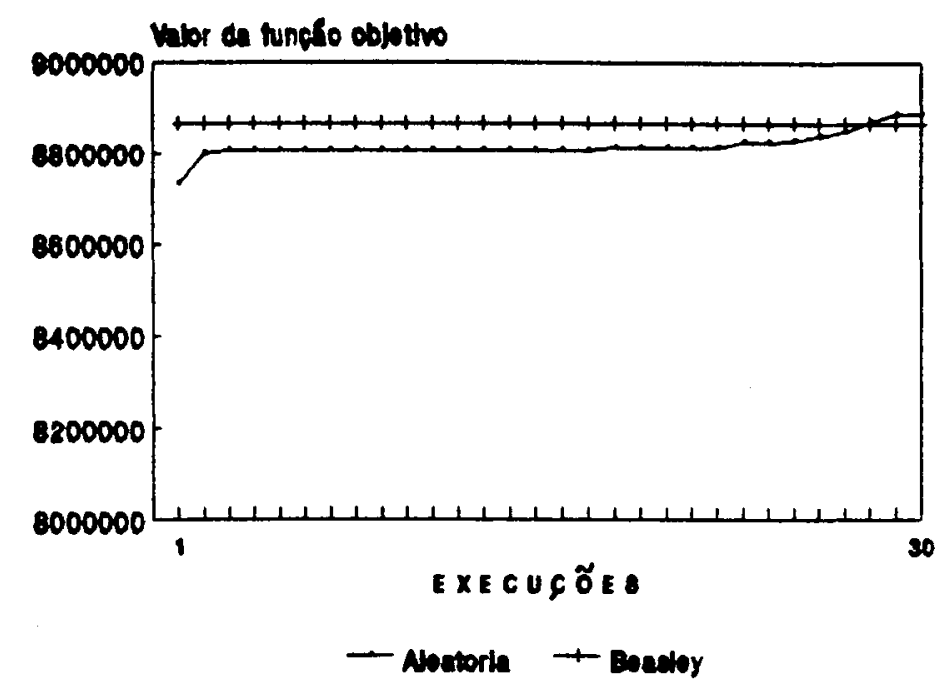

gráfico 6.2.

Heuristica de Beasley $x$ Escolha aleatória restrita

Obteve-se soluçôes melhores se comparadas com a escolha aleatória irrestrita, porém, ainda assim, soluções piores em média, quando comparadas com o resultado de Beasley.

Como a heurística de Beasley, em comparação com geração aleatória dos conjuntos de discretizaçôes, mostrou-se mais adequada, optou-se por utilizá-la neste trabalho. 


\subsection{Procedimento HC_DP2}

Foi utilizado o algoritmo HC_DF com abordagem em grafo-E/OU para o problema de corte, inicialmente apresentado por Morábito et al (1989), e programado na linguagem Pascal.

\subsubsection{Combinação da regra de simetria com a heuristica de Beasley}

Quando a heuristica de descarte de pontos é utilizada, a regra de simetria não é mais válida. Tanto Beasley quanto Morábito, ao determinarem os subconjuntos de discretizaçóes utilizaram o comprimento total, bem como a largura total. Embora a simetria não seja mais válida, propốe-se utilizá-la como heuristica, isto $e$, gerar pontos de discretizações ao Iongo de $(\mathrm{L} / 2, \mathrm{~W} / 2)$.

Nas tabelas a seguir designa-se HC_DF1 ao algoritmo com abordagem E/OU encontrado em Morábito et al., e HC_DF2 para o algoritmo HC_DF com a inclusão da regra de simetria na geração dos pontos de discretizações dos conjuntos $X$ e $Y$, que está sendo proposto.

Comparações também foram feitas com o algoritmo de Beasley, baseado em programaçăo dinâmica, com utilização da heuristica para limitar o número máximo de elementos no conjunto de discretizações ao longo de (L,W).

As melhores soluções (heuristicas) apresentadas para o problema de Beasley estão na Tabela 6.2 , onde $M$ representa 0 limite máximo de pontos de discretizações; $|X|$ e $|\mathbf{Y}|$ representam a cardinalidade dos conjuntos de discretizações; $\alpha$ e $\beta$ sắo valores para as heuristicas discutidas em (4.5.2); \# nós significa o número de nós analisados; e depth a profundidade de cada árvore E/OU a partir de um nó raíz. 
Tabela 6.2.

Soluçóes para o problema de Beasley

\begin{tabular}{llllllllll}
\hline Método $M$ & $|X|$ & $|Y|$ Depth & $\alpha$ & $\beta$ & \#nós & soluçäo & $\begin{array}{c}\text { área } \\
\text { ocupada } \\
(8)\end{array}$ \\
\hline 1 & 125 & 125 & 109 & - & - & - & - & 8.868 .950 & 98,5224 \\
2 & 200 & 182 & 161 & 3 & 0,990 & 1,000 & 245 & 8.944 .026 & 99,3781 \\
3 & - & - & - & - & - & - & - & 8.997 .780 & 99,9757 \\
4 & 100 & 86 & 93 & 3 & 0,999 & 0,999 & 163 & 8.997 .780 & 99,9757 \\
\hline
\end{tabular}

Os métodos $1,2,3$ e 4 da tabela 6.2 referem-se respectivamente, aos resultados apresentados por Beasley (1985a) com programaçấo dinâmica, Morábito et al (1992) com procedimento HC_DF1, Morábito et al (1992b) com procedimento 2-estagiado e o procedimento HC_DF2 que está sendo proposto.

Ao serem avaliados os parâmetros utilizados nos procedimentos de resolução do problema apresentado por Beasley, percebe-se que alguns destes parâmetros mostram-se significativamente diferentes. Nota-se que:

(i) Depth $=3$ foi utilizado no HC_DF2 para que se pudesse comparar com o resultado do HC_DF1 apresentado por Morábito et al. Porém, para este problema especifico, a mesma solução foi encontrada com depth $=1$. (Note que o método HC_DF com depth=1, torna-se Hill-climbing puro).

(ii) Os parâmetros a e $\beta$ para o HC_DF2 foram obtidos através de avaliações comparativas, utilizando-se o problema em questão, cujas comparações serẫo apresentadas a seguir. Os valores de 
$\alpha=0,99$ e $\beta=1,00$ utilizados em HC_DFl quando aplicados em HC_DF2 conduzem à um tempo computacional inviável.

(iij)A solução encontrada no HC_DF2 conduz ao melhor resultado para o problema encontrado na literatura até o presente momento. Tal soluçäo fornece uma área ocupada de 99,97578 da área da placa, o que, se comparado ao resultado apresentado por Beasley, nos fornece um aumento de 1,45338 da área ocupada.

(iv) Morábito et al (1992) obtiveram o mesmo resultado apresentado pelo HC_DF2, porém considerando a restrição no padrấo de corte de 2-estagiado.

Vale salientar que, mesmo obtendo este resultado por meio de dois enfoques diferentes, dados pelos problemas estagiado e não-estagiado, e tendo uma área ocupada muito grande, nâo se pode garantir que a soluçăo encontrada é ótima, pois foram utilizadas heuristicas que eliminaram padrões de cortes durante o processo de resolução do problema.

\subsubsection{Parametros}

Para que se pudesse estimar (avaliar) os parâmetros $M$, Depth, $\alpha$ e $\beta$ utilizados no procedimento HC_DF2, foi utilizado novamente $\circ$ exemplo de Beasley (Tabela 6.1) e procedeu-se variações dos parâmetros utilizando-se o algoritmo HC_DF2. Algumas variações estẫo exibidas na tabela 6.3 .

Nota-se na Tabela 6.3 que com os valores de $\alpha=0,99$ e/ou $\beta=0,99$ não é possivel encontrar a melhor soluçăo para o problema. Porém, quando $B=0,999$ é utilizado, a melhor solução para o problema é alcançada tanto para $\alpha=0,999$, quanto para $\alpha=1,000$, inclusive gerando $\circ$ mesmo número de nós. Além disto, as profundidades 2 e 3 conduzem às mesmas soluções, porém isto nắo é 
regra geral pois quanto maior a profundidade, maior é a chance de se obter um padráo melhor.

Outros valores para $\alpha$ e foram testados, mas os valores apresentados conduzem às melhores soluções.

Tabela 6.3

Variaçð̃es dos parâmetros - HC_DF2

\begin{tabular}{|c|c|c|c|c|c|c|c|}
\hline$M$ & $|x|$ & $|\mathbf{Y}|$ & Depth & $\alpha$ & $\beta$ & \#nós & soluçăo \\
\hline 100 & 86 & 93 & $\begin{array}{l}2 \\
3\end{array}$ & 0,990 & 0,990 & $\begin{array}{l}23 \\
23\end{array}$ & $\begin{array}{l}8.973 .360 \\
8.973 .360\end{array}$ \\
\hline 100 & 86 & 93 & $\begin{array}{l}2 \\
3\end{array}$ & 0,990 & 0,999 & $\begin{array}{r}97 \\
151\end{array}$ & $\begin{array}{l}8.973 .360 \\
8.973 .360\end{array}$ \\
\hline 100 & 86 & 93 & $\begin{array}{l}2 \\
3\end{array}$ & 0,999 & 0,990 & $\begin{array}{l}23 \\
23\end{array}$ & $\begin{array}{l}8.973 .360 \\
8.973 .360\end{array}$ \\
\hline 100 & 86 & 93 & $\begin{array}{l}2 \\
3\end{array}$ & 0,999 & 0,999 & $\begin{array}{l}103 \\
163\end{array}$ & $\begin{array}{l}8.997 .780 \\
8.997 .780\end{array}$ \\
\hline 100 & 86 & 93 & $\begin{array}{l}2 \\
3\end{array}$ & 1,000 & 0,999 & $\begin{array}{l}103 \\
163\end{array}$ & $\begin{array}{l}8.997 .780 \\
8.997 .780\end{array}$ \\
\hline 100 & 86 & 93 & $\begin{array}{l}2 \\
3\end{array}$ & 1,000 & 0,990 & $\begin{array}{l}23 \\
23\end{array}$ & $\begin{array}{l}8.973 .360 \\
8.973 .360\end{array}$ \\
\hline 200 & 180 & 170 & $\begin{array}{l}2 \\
3\end{array}$ & 0,990 & 0,990 & $\begin{array}{l}27 \\
27\end{array}$ & $\begin{array}{l}8.973 .360 \\
8.973 .360\end{array}$ \\
\hline 200 & 180 & 170 & $\begin{array}{l}2 \\
3\end{array}$ & 0,990 & 0,999 & $\begin{array}{l}147 \\
217\end{array}$ & $\begin{array}{l}8.973 .360 \\
8.973 .360\end{array}$ \\
\hline 200 & 180 & 170 & $\begin{array}{l}2 \\
3\end{array}$ & 0,999 & 0,990 & $\begin{array}{l}27 \\
27\end{array}$ & $\begin{array}{l}8.973 .360 \\
8.973 .360\end{array}$ \\
\hline 200 & 180 & 170 & $\begin{array}{l}2 \\
3\end{array}$ & 0,999 & 0,999 & $\begin{array}{l}155 \\
235\end{array}$ & $\begin{array}{l}8.997 .780 \\
8.997 .780\end{array}$ \\
\hline 200 & 180 & 170 & $\begin{array}{l}2 \\
3\end{array}$ & 1,000 & 0,999 & $\begin{array}{l}155 \\
235\end{array}$ & $\begin{array}{l}8.997 .780 \\
8.997 .780\end{array}$ \\
\hline 200 & 180 & 170 & $\begin{array}{l}2 \\
3\end{array}$ & 1,000 & 0,990 & $\begin{array}{l}23 \\
23\end{array}$ & $\begin{array}{l}8.973 .360 \\
8.973 .360\end{array}$ \\
\hline
\end{tabular}


Como se está trabalhando com heuristicas, optou-se por utilizar $\alpha=0,999$ e $\beta=0,999$, além de depth $=3$ e $M=100$; estes dois últimos em virtude de serem passiveis de comparação com outros exemplos citados na literatura.

Cinco exemplos gerados aleatoriamente e apresentados em Morábito et al (1992), exibidos na tabela 6.4, foram comparados com O HC_DF 2 e os resultados eståo na tabela 6.5 .

tabela 6.4 .

Exemplos gerados aleatoriamente

\begin{tabular}{|c|c|c|c|c|c|}
\hline $\begin{array}{l}\text { Problema } \\
(L, W)\end{array}$ & $\frac{1}{(100,156)}$ & $\begin{array}{c}2 \\
(253,294)\end{array}$ & $\begin{array}{c}3 \\
(318,473)\end{array}$ & $\begin{array}{l}4 \\
(501,556)\end{array}$ & $\begin{array}{l}5 \\
(750,806)\end{array}$ \\
\hline \multirow{10}{*}{$\begin{array}{l}\left(l_{i}, w_{i}\right) \\
i=1,10\end{array}$} & $(27,32)$ & $(130,130)$ & $(141,128)$ & $(136,113)$ & $(205,163)$ \\
\hline & $(16,50)$ & $(49,134)$ & $(109,151)$ & $(81,177)$ & $(121,257)$ \\
\hline & $(47,66)$ & $(45,52)$ & $(76,142)$ & $(237,237)$ & $(356,343)$ \\
\hline & $(37,46)$ & $(64,134)$ & $(204,124)$ & $(184,163)$ & $(276,236)$ \\
\hline & $(31,51)$ & $(38,100)$ & $(110,165)$ & $(153,182)$ & $(230,264)$ \\
\hline & $(47,51)$ & $(121,146)$ & $(142,168)$ & $(233,183)$ & $(350,266)$ \\
\hline & $(48,44)$ & $(48,123)$ & $(82,238)$ & $(241,155)$ & $(361,225)$ \\
\hline & $(49,45)$ & $(83,79)$ & $(169,75)$ & $(246,160)$ & $(369,232)$ \\
\hline & $(59,78)$ & $(42,187)$ & $(165,185)$ & $(296,278)$ & $(445,404)$ \\
\hline & $(21,87)$ & $(112,92)$ & $(162,184)$ & $(103,310)$ & $(155,559)$ \\
\hline
\end{tabular}

Novamente, o valor de cada peça $\left(l_{i}, w_{i}\right)$ é dado por $v_{i}=l_{i} \cdot w_{i}, \quad i=1, \ldots, m$. 
Tabela 6.5.

Soluçơes para os problemas aleatórios

\begin{tabular}{cccccr}
\hline Problema & $\begin{array}{c}\text { Soluçắ } \\
\text { otima }\end{array}$ & $\begin{array}{l}\text { Soluçăo } \\
\text { HC_DF1 }\end{array}$ & $\begin{array}{c}\text { \# nós } \\
\text { HC_DF1 }\end{array}$ & $\begin{array}{c}\text { Soluçăo } \\
\text { HC_DF2 }\end{array}$ & $\begin{array}{r}\text { nós } \\
\text { HC_DF2 }\end{array}$ \\
\hline 1 & 15.024 & 15.024 & 741 & 15.024 & 11 \\
2 & 73.176 & 72.172 & 159 & 72.172 & 3 \\
3 & 142.817 & 142.817 & 1.515 & 142.817 & 123 \\
4 & 265.768 & 265.768 & 977 & 265.768 & 5 \\
5 & 577.882 & 577.882 & 989 & 577.882 & 5 \\
\hline
\end{tabular}

Nota-se que somente a soluçăo ótima do problema 2 não foi encontrada.

Para a obtençầo das soluções foram utilizados, pelos dois procedimentos, depth=3 e $M=155$, enquanto que HC_DF1 utilizou $\alpha=0,99$ e $\beta=1,00$ e 0 HC_DF2 utilizou $\alpha=0,999$ e $\beta=0,999$. Uma evidente diminuição no número de nós gerados na resolução de tais problemas foi alcançada, o que confirma a importancia dos parâmetros a e $\beta$, bem como da combinação da regra de simetria no conjunto de discretizaçôes. Nota-se que a diminuiçấo no número de nós gerados conduz a uma equivalente diminuição do esforço computacional empregado na resolução dos problemas.

Baseado no fato de que, para o problema prático exibido por Beasley, a solução dada pelo problema 2-estagiado é a mesma encontrada neste trabalho através do HC_DF2, analisou-se 0 desempenho destes dois enfoques. Utilizou-se os resultados apresentados por Morábito et al (1992a), que considera a geraçã̃o aleatória de 50 exemplos "grandes" para uma placa de $L=1000$ e $W=1000$, conforme a tabela 6.6 . 
Tabela 6.6.

Soluçbes dos problemas aleatórios $(L, W)=(1000,1000)$

\begin{tabular}{rlll}
\hline$m$ & $\begin{array}{l}\text { Programaçăo } \\
\text { Dinamica }\end{array}$ & $\begin{array}{l}\text { Soluçåo } \\
\text { 2-estagiado }\end{array}$ & $\begin{array}{l}\text { Soluçáo } \\
\text { HC_DF2 }\end{array}$ \\
\hline 10 & 98,00 & 98,26 & 98,44 \\
20 & 98,62 & 99,10 & 99,20 \\
50 & 99,07 & 99,65 & 99,51 \\
100 & 99.45 & 99,88 & 99,55 \\
\hline
\end{tabular}

Foram considerados, para a resoluçăo através do HC_DF2, $M=100$, depth=3, $\alpha=0,999$ e $\beta=0,999$. Os comprimentos $l_{i}$ e larguras $w_{i}$ das peças foram gerados aleatoriamente dentro do intervalo $[0,05 \mathrm{~L}, 0,50 \mathrm{~L}]$ e $[0,05 \mathrm{~W}, 0,50 \mathrm{~W}]$, respectivamente, com $v_{i}=I_{i} \cdot w_{i}$.

As soluçốes da tabela 6.6 dizem respeito à média das soluçôes encontradas para os exemplos gerados, e estâo apresentadas pelo percentual de ocupação das placas; $m$ indica a quantidade de peças diferentes a serem produzidas.

Da análise da tabela 6.6 nota-se que, comparando-se as soluçôes 2-estagiado e HC_DF2, os resultados dependem da quantidade de peças diferentes a serem produzidas. Para problemas com menor número de peças, O HC_DF2 maximiza comparativamente a área ocupada. Inversamente, para problemas com muitas peças, o resultado é melhor no 2-estagiado. Uma comparação entre os valores médios de ocupaçăo das placas resulta em um valor de apenas 0,0408 , a favor do 2-estagiado.

Comparando-se os dois algoritmos que utilizam-se da heuristica de discretizaçäo proposta por Beasley, percebe-se que existe uma melhora significativa da eficiência no HC_DF2, relativamente ao algoritmo baseado em programação dinâmica. 
Novamente, uma comparaçăo entre os valores médios de ocupaçăo das placas resulta em um valor de 0,3958 , sempre a favor do HC_DF2.

Para ilustrar as conclusóes apresentadas a partir da tabela 6.6, é exibido um exemplo publicado em Morábito et al. (1991), gerado aleatoriamente e mostrado na tabela 6.7. Na tabela 6.8 apresenta-se os resultados deste problema.

Tabela 6.7 .

Exemplo apresentado em Morábito et al (1991)

\begin{tabular}{llllll}
\hline$(L, W)$ & $(4051,4742)$ & $\left(1_{i}, w_{i}\right) i=1, \ldots 10$ & \\
\hline$(1633,2275)$ & $(1249,483)$ & $(321,359)$ & $(277,2231)$ & $(1580,882)$ \\
$(636,1395)$ & $(2026,1573)$ & $(283,1880)$ & $(1103,632)$ & $(1727,449)$ \\
\hline
\end{tabular}

Tabela 6.8.

Soluçôes dos problemas aleatórios da tabela 6.7.

\begin{tabular}{lcc}
\hline Método & Soluçäo & $\begin{array}{c}\text { Area } \\
\text { ocupada (8) }\end{array}$ \\
\hline Programaçăo Dinámica & 18.410 .810 & 95,841 \\
2-estagiado & 18.688 .992 & 97,289 \\
HC_DF2 & 18.693 .342 & 97,311 \\
\hline
\end{tabular}

Os autores apresentaram a soluçâo obtida pela fórmula recursiva, sendo $M=100$, implicando em $|X|=47$ e $|Y|=80$, e a solução obtida pela limitação do padrão de corte em 2-estágios. 0 mesmo exemplo foi executado no HC_DF2, com $M=50$, para que pudesse ser passivel de comparação, resultando em $|x|=28$ e $|y|=33$, $\operatorname{com} \alpha=0,999$ e $\beta=0,999$, o que conduziu a uma soluçá melhor do 
que as resultantes destes outros procedimentos. (Note que as cardinalidades de $X$ e $Y$ para 0 HC_DP2 sáo significativamente menores do que as cardinalidades utilizadas pelo procedimento de programaçáo dinâmica) 


\section{CONCLUSÓES}

- método heuristico de geraçăo dos conjuntos de discretizaçốes, proposto por Beasley (1985a) para problemas de cortes guilhotinado não-estagiado, mostrou-se eficiente, quando comparado com a geraçăo aleatória dos conjuntos de discretizaçóes.

A abordagem em grafo-E/OU, comumente utilizada na área de Inteligência Artificial, com a utilização da estratégia de busca hibrida "Hill-Climbing" e "Depth-First - Backtracking", para a geraçắ de um padrăo de corte para o problema de corte bidimensional guilhotinado năo-estagiado e irrestrito, mostrou-se realmente eficiente.

Outrossim, percebe-se ser possivel melhorar a performance do algoritmo HC_DF através da utilização dos parâmetros $\alpha$ e $\beta$ diferentes daqueles propostos inicialmente por Morábito et al (1992). Indica-se os valores $\alpha=0,999$ e $\beta=0,999$.

Finalmente, percebe-se que a combinação da regra de simetria com a heurística de Beasley, reduzindo 0 intervalo de discretização ao longo de $\mathrm{L} / 2$ e $\mathrm{W} / 2$, conduz a resultados computacionais mais eficazes do que a heuristica de Beasley ao longo de $\mathrm{L}$ e $W$. 


\section{REFERÊNCIAS BIBLIOGRÁFICAS}

ALBANO, A., SAPUPPO, G. (1980). Optimal allocation of two dimensional irregular shapes using heuristic search methods. IBEE Transactions on systems, man, and cybernetics. v.10, p. 242-8.

ARCARO, V. (1988). Recorte de estoque unidimensional. săo Carlos: ICMSC. 54p. Dissertaçăo (Mestrado em Ciencias da Computação e Matemática Computacional) - Instituto de Ciencias Matemáticas de são Carlos, Universidade de săo Paulo.

BEASLEY, J. E. (1985a). A Algorithm for unconstrained two-dimensonal guilhotine cutting. Journal of the Operational Research Society. v.36, n.4, p.297-306.

. $(1985 \mathrm{~b}) . \quad$ An exact two-dimensional non guilhotine
cutting tree search procedure. Operations Research. v.33,
p.49-64.
CHRISTOFIDES, N., wHITLOCK, C. (1977). An algorithm for
two-dimensional cutting problems. Operations Research. v.25,
n.1, p.30-44.

DAGLI, C.H.(1990). Knowledge-based systems for cutting stock problems. European Journal of Operational Research. v.44, p. 160-6.

DYCKHOFF, H. et. al. (1985). Trim loss and related problems. Omega. v.1, p.59-72.

DYCKHOFF, H. A (1990). Typology of cutting and packing problems. European Journal of Operational Research. v.44, p.145-59.

DYSON, R.G., GREGORY, A.S.(1974). The cutting stock problem in the flat glass industry. Operational Research Quartely. v.25,p.41-53 
EILON, S., CHRISTOFIDES, N. (1971). The loading problem. Management science. v.17, p.259-68.

BISBMANN, $K$ (1957). The trim problem. Management Science. v.3, p. 279-84.

FARLEY, A.A. (1988). Mathematical programming models for cutting stock problems in the clothing industry. Journal of the Operational Research Society. v.39, p.41-53.

- (1990). The cutting stock problem in the canvas industry. Buropean Journal of Operations Research. v.44, p. 247-55.

FERREIRA, J.S., NEVES, M.A., FONSECA e CASTRO, P. (1990). A two-phase roll cutting problem. Buropean Journal of Operations Research. v.44, p.185-96.

GILMORE, P.C., GOMORY, R.E. (1961), A linear programming approach to the cutting stock problem. Operations Research. v.9, p. $849-59$.

.(1963). A linear programming approach to the cutting stock problem - part II. Operations Research. v.10, p.863-88. . (1965). Multistage cutting stock problems of two and more dimensions. Operations Research. v.13, p.94-120. . (1966). The theory and computation of Knapsack functions. Operations Research, v.14, p.1045-74.

HAESSLER, R.W. (1971). A heuristic programming soluction to a non-linear cutting stock problem. Management Science. v.17B, p. 793-802. 
HAESSLER, R. W. (1980). A note on computacional modifications to the Gilmore-Gomory cutting stock algorithm. Operations Research. v.28, p.1001-5..

HERZ J.C. (1972). Recursive computacional procedure for two-dimensional stock cutting. IBM Journal Research and Development. v.15, p.462-9.

KVICTA, A.M. (1988). Resolucion de problemas con inteligencia artificial. Curitiba: EBAI. 285p.

MORABITO, R.N. (1989). Corte de estoque bidimensional. Săo Carlos: ICMSC, 1989.57p. Dissertaçăo (Mestrado em Ciências de Computação e Matemática Computacional ) - Instituto de Ciências Matemáticas de Sắo Carlos, Universidade de são Paulo).

- (1992). Uma abordagem em grafo-e-ou para o problema do empacotamento: aplicaçầo ao carregamento de paletes $e$ contêineres. Tese. (Doutorado em Engenharia de Transportes )Escola de Engenharia de Săo Carlos, Universidade de São Paulo.

MORABITO, R. N., ARENALES, M. N., ARCARO V. F. (1989). An And-or-graph representation to generate cutting patterns for the two-dimensional cutting problem. In: Alio-Buro Workshop on Practical Combinatorial optimization. Rio de Janeiro. p.1-20.

(1992). An And-or-graph approach for two-dimensional cutting problems. European Journal of Operational Research. v. 58, p. 263-71.

MORABITO, R.N., ARENALES, M.N. (1991). On solving large two-dimensional guilhotine cutting problems. Notas do ICMSC. Säo Carlos.

(1992a). On solving large two-dimensional guilhotine cutting problems. Ed. revisada. Notas do ICMSC. Säo Carlos. 
MORABITO, R.N., ARBNALES, M.N. (1992b). Staged and constrained two-dimensional cutting problems: a new approach. Notas do ICMSC. såo Carlos.

NILSSON. N.J.(1971). Problem-solving methods in artificial intelligence. New York: McGraw-Hill. 255p.

PAULL, A.E., WALLTER, J.R. (1955). The trim problem: an application of linear programming to the manufacture of newsprint paper. Econometria. v.23, p.336.

PEARL, J. (1984). Heuristic: intelligence search strategies for computer problem solving. Addison-Wesley, Reading, MA. 382p.

RICH, E. (1983). Artificial intelligence, McGraw-Hill, New York.

SARIN, S. (1983). The mixed disc packing problem: part I. IIEE Transactions. v.15, p. 37-45.

STAINTON, R.S. (1977). The cutting stock problem for the stockholder of steel reinforcement bars, Operational Research Quartely. v.13, p.713-9.

SHIRAI, Y, TSUJII, J. (1988). Inteligencia artificial: conceitos, técnicas e aplicaçôes. Portugal: Europa-América. 178p.

SWEENEY, P.E., HAESSLER, R.W(1990). One-dimensional cutting stock decisions for rolls with multiple quality grades, Buropean Journal of Operations Research. v.44, p.224-31.

TILANUS, C.B., GERHARDT, C. (1976). An Application of cutting stock in the steel industry, Operational Research. v.75, p. 669-75.

YEN, B.J. (1991). Heuristics for sequencing cutting patterns, Buropean Journal of Operational Research. v.55, p.183-90. 